\title{
COORDENADAS DEL ASOCIACIONISMO PROFESIONAL DE LOS DOCENTES. ESTADO DE LA CUESTIÓN EN ESPAÑA
}

\author{
Milestones in the affiliation to professional teachers' associations. \\ The situation in Spain
}

\section{Aida Terrón Bañuelos*}

Fecha de recepción: 07/10/2014 • Fecha de aceptación: 23/10/2014

Resumen. Este trabajo se organiza en dos planos de análisis diferenciados. Se presentan, en un primer momento, los hitos más significativos del proceso de construcción del asociacionismo docente en España, desde las últimas décadas del siglo XIX hasta la actualidad; se procura identificar la naturaleza de sus organizaciones profesionales (corporativa o sindical) así como la tipología de sus reivindicaciones frente a las políticas educativas desplegadas por los sucesivos regímenes políticos (monarquía, república, dictadura y democracia parlamentaria). En la segunda parte se revisa y caracteriza la investigación producida en nuestro país durante los últimos años en este ámbito historiográfico, haciendo breves incursiones de carácter comparativo con la de los países de nuestro entorno (Francia, Portugal e Italia).

Palabras clave: Asociacionismo docente. España. Educación Comparada. Sindicalismo docente.

Abstract. This article makes use of two different analytical perspectives. First, we examine some of the milestones in the process of alliance and affiliation in teachers' associations that has taken place starting in the final decades of the nineteenth century. In doing so we describe the different kinds of professional organizations (some corporative, others of a union model) as well as the kinds of demands and claims they made regarding the educational policies put into place by the successive political regimes (monarchy, republic, dictatorship and parliamentary democracy). The second part of the article traces the research carried out in Spain on the subject in recent years, including brief references, for comparison's sake, to the panorama in neighboring countries such as Portugal, France and Italy.

Key Words: Teachers Associations. Spain. Comparative Education. Unions.

\footnotetext{
* Facultad de Formación del Profesorado y Educación. Universidad de Oviedo. C/ Aniceto Sela, s/n. 33005 Oviedo. España. aterron@uniovi.es
}

Cómo citar este artículo: Terrón Bañuelos, Aida, «Coordenadas del asociacionismo profesional de los docentes. Estado de la cuestión en España», Historia y Memoria de la Educación, 1 (2015): 93-130. 
Encontrar una forma de asociación que defienda y proteja con toda la fuerza común a la persona y bienes de cada asociado, por lo cual, uniéndose cada uno a todos, no obedezca, sin embargo, más que a sí mismo y permanezca tan libre como antes (J.-J. Rousseau, El contrato social, 1762).

\section{INTRODUCCIÓN}

El derecho de asociación, instaurado por liberalismo político, tuvo, como se sabe, un penoso discurrir en la Europa decimonónica, siendo en muchas ocasiones frenado (e incluso ocasionalmente prohibido) con argumentos rousseaunianos de respeto a la voluntad general y temor a levantar barreras entre los individuos y el Estado que pudiesen fraccionar el interés colectivo. En nuestro país, donde frecuentemente fue considerado como una amenaza a la libertad y al orden constituido, la carrera de obstáculos que el ejercicio de ese derecho habría de superar para su reconocimiento pleno, puede resumirse, según la historiadora Maza Zorrilla, en una imagen crónica: «la lucha en el siglo XIX por reclamar ese derecho y la no menos ardua del siglo XX por intentar usarlo»; y es que «consumada la conquista —continúa Zorrilla- el siglo se salda con un 70\% de restricción o encorsetamiento de libertades» (primer tercio de siglo, guerra civil y franquismo) y un exiguo 30\% de islotes de libertad y pluralismo (quinquenio republicano y democracia formal), quedando circunscrito su libre y democrático ejercicio a un lapso de apenas treinta años (cuarenta a día de hoy). ${ }^{1}$

\footnotetext{
${ }^{1}$ Elena Maza, «El asociacionismo y sus formas», en Las claves de la España del siglo XX. La modernización social, coord. Antonio Morales (Madrid: Sociedad Estatal Nuevo Milenio, 2001), 335-366 (cita en p. 339). El derecho de asociación retardó su regulación formal en España hasta la ley de 30 de junio de 1887, ley que regirá durante casi un siglo la disciplina de las asociaciones de forma directa o supletoria, si bien ya la Constitución de 1869 lo había proclamado como fundamental e irrenunciable del ser humano y la de 1876 lo limitase a actividades inocuas (recreo, instrucción, beneficencia, caridad, previsión, socorros mutuos, cooperación, confesionalidad, partidos dinásticos). La Dictadura de Primo de Rivera mantendrá solo formalmente las formas asociativas reivindicativas (que, frente al sindicalismo de clase, defendían la vía profesional de nuevo cuño, neutralizada y bajo control de los poderes públicos) siendo durante el periodo republicano cuando se produzca un definitivo avance (la Constitución de 1931 recogía el derecho a la sindicación y asociación libres, regulándose, por primera vez en el derecho español, la libre asociación de obreros y patronos). El «cerrojazo franquista» se efectúa con el Decreto de Unificación de 1937, que prohíbe los partidos políticos, los sindicatos y todas las asociaciones proclives a la república. Una norma de 1941, que deroga la ley de asociaciones de 1887, exige la aprobación ministerial para constituir asociaciones, excepto las católicas y las comprendidas en Falange Española Tradicionalista y de las Juntas de Ofensiva Nacional Sindicalista (FET y de las JONS); prohibición imperante hasta 1965, cuando se admiten sólo las de carácter cultural, deportivo y recreativo: «poco podemos transmitir de la realidad asociativa del franquismo que no suene a desamparo, superficialidad, localismo y domesticación» (p. 356); el derecho de asociación será finalmente recogido en el artículo 22 de la Constitución de 1978.
} 
Conviene recordar esta traumática peripecia — pareja a una traumática realidad política- para explicar la «marca España» también en el comportamiento asociativo; y no perder de vista que mientras que entre 1960 y 1985 los países de nuestro entorno alcanzaban las tasas de sindicalización más altas de la historia (incluidos los docentes: entre el 75 y el 90\% de los ingleses, los dos tercios de los alemanes y tasas incluso mayores en Francia), ${ }^{2}$ en España se estaba asistiendo a los primeros conatos de un sindicalismo clandestino, violentamente reprimido, que, con el paso del tiempo, una vez recuperadas las libertades y perfectamente legalizado y «homologado», nunca llegaría a sobrepasar tasas superiores a un $25 \%$ entre el colectivo enseñante.

Digamos que, en la España reciente, la libertad de asociación nos pilló con el paso cambiado, llegando a ella cuando, tras su época de apogeo, comenzaba en la Europa occidental y en la práctica totalidad del mundo industrializado la curva negativa de un sindicalismo "a la defensiva» que asistía (que asiste) a una merma constante de afiliación: «tras rozar medias incluso superiores al $45 \%$ a finales de los 70 , la afiliación ha caído en torno al 30\% en los países de la OCDE, al 26\% en la UE-15 y al 25\% en la UE27 », oscilando entre el 10 y el $20 \%$ en las mayores potencias económicas mundiales (EEUU, Japón, Alemania o Rusia). Sólo en los últimos años han empezado a observarse leves modificaciones de tendencia en algunos países como Francia, donde el declive se ha ralentizado, o los Países Bajos y España, en los que se observa incluso una ligera recuperación. ${ }^{3}$ La baja tasa de partida de nuestro país (el 18,4\% en 1977) coloca «en su sitio», sin embargo, el optimista término de «recuperación» afiliativa: la cota más alta alcanzada entre nosotros (el 19,5\% en 1995) ${ }^{4}$ constituye un raquítico porcentaje que expresa la profundidad de la brecha que nos sigue distanciado de una

\footnotetext{
${ }^{2}$ Los datos proceden de un infrecuente e interesante trabajo comparativo sobre sindicalismo docente: Laurent Frajerman et al., "Les syndicalismes enseignants devant l'èvolution des systémes éducatifs et des identités professionnelles. Allemagne de l'Ouest, Angleterre, Belgique, France», en L'apogée des syndicalismes en Europe Occidentale. 1960-1985, dirs. Patrick Pasture, Michel Pigenet y Jean-Louis Robert (Paris: Publications de la Sorbonne, 2005), 51-80.

3 Salvo Leonardi, «El modelo sindical italiano», Observatorio confederal de afiliación, de la Fundación $1^{\circ}$ de Mayo, 2 (2011): 6-22 (cita en p. 6).

${ }^{4}$ En 2010 había bajado al 18,9\%. Véase Pere J. Beneyto, «Desmontando el discurso antisindical», Anuario sociolaboral de la Fundación $1^{\circ}$ de Mayo, (2012): 525-539. El autor refiere esa ralentización en el descenso, pese al discurso machaconamente repetido de la baja afiliación y la escasa representatividad de un sindicalismo limitado a viejos sectores tradicionales o, «en la versión más sofisticada de este viejo mantra» (p. 525), a los insiders - trabajadores fijos de las grandes empresas y de los servicios- frente al abandono en que mantiene a los outsiders — trabajadores precarios y parados-.
} 
Europa sólo nominalmente «común», herencia de un franquismo —y de un postfranquismo- que se proyecta aún en el presente.

Se sabe poco de la situación afiliativa del sector docente en España. La «Encuesta al profesorado de primaria y secundaria de la enseñanza pública» realizada en 1993 proporciona los primeros datos «históricos» desde los que determinar la tendencia; entonces un (algo abultado) 25\% de la muestra se declaraba afiliada a algún sindicato, ${ }^{5}$ con una desigual distribución por sectores que se consolidaría en los años siguientes (Educación General Básica, un 32\%; Bachillerato Unificado y Polivalente, un 13,3\%; y Formación Profesional, un 11,7\%). Dieciséis años después la afiliación en el sector no sólo no caía, sino que experimentaba incluso un leve incremento, alcanzando un $26,6 \%$ en el año $2009,{ }^{6}$ lo cual no obsta -e incluso puede contribuir a explicarlo- para que la opinión negativa sobre el sindicalismo docente surja desde las más inesperadas esquinas, sea subrayando su corporativismo, sea afirmando su connivencia con la "Razón de Estado» más que con la «sociedad civil», habiendo quienes llegan incluso a negarle, en una sorprendente pirueta, su contrastada ligazón con la dinámica de la renovación pedagógica.

$\mathrm{Al}$ respecto, y al hilo de la realización de este trabajo, leía en el Cuaderno de campo del sociólogo Mariano Fernández Enguita (6-2-2014: «De sindicatos: obreros y docentes») su reflexión sobre el cambio operado en la base social y en el papel de unos sindicatos «menos obreros cada vez y más poblados por las clases medias funcionales o la nueva pequeña burguesía», que habría que contabilizar como un "plus para los profesores o un minus para los sindicatos», y que refleja que

el funcionariado y el semi-funcionariado [...] han encontrado en el movimiento inercial de los sindicatos y en el discurso retórico de la izquierda (con lo cual no quiero decir ni que el legado de los sindicatos sea sólo inercia ni que el discurso de la izquierda sea sólo retórica, pero si que también lo contienen) espléndidos instrumentos para eficaces estrategias corporativas.

\footnotetext{
${ }^{5}$ Cecilia Navarro Sada (coord.), Encuesta al profesorado de primaria y secundaria de la enseñanza pública. Opiniones y actitudes ante las condiciones de trabajo (Madrid: CIDE, 1993); las autoras consideraban este porcentaje «algo elevado, en contraste con la afiliación real, que no puede establecerse con exactitud dadas las reticencias sindicales a proporcionar datos de afiliación».

${ }^{6}$ El 28,4\% según la CNAE (Clasificación Nacional de Actividades Económicas). Ese año el 17,2\% de los ocupados (y el 19,9\% de los asalariados) estaba afiliado.
} 
Desde una esquina diferente, el pedagogo Jaime Martínez Bonafé opina «Sobre las relaciones entre el sindicalismo docente y la renovación pedagógica». ${ }^{7}$ Habla, en este caso, un «viejo afiliado sindical, que siempre mantuvo un cierto recelo al sindicalismo integrado en el sistema de las democracias formales $[. .$.$] y que pretende ahora, con su palabra, contribuir a la reflexión y$ análisis sobre el modo en que el sindicalismo se comporta con la experiencia social y política de la renovación pedagógica» (p. 276); legitimadora atalaya que le permite afirmar, resueltamente, la absoluta (e incapacitante, desde el punto de vista sindical) desligazón de aquél respecto de ésta:

\begin{abstract}
Mi hipótesis es que vivimos un claro divorcio entre el discurso sindical y el discurso pedagógico renovador, y que el sindicalismo olvidó los referentes pedagógicos del proyecto de escuela pública [...] ¿Cuál es la posición de los sindicatos ante el proyecto político de la ciudad educadora? [...] ¿desde qué modelo de escuela analizamos qué es concretamente lo que pone en peligro el neoliberalismo en la educación? [...] ¿han de negociar los maestros y las maestras el proyecto cultural del currículo? [...] ¿Somos laicos? [...] ¿Investigación del profesor? ¿por qué? [...] ¿libros de texto gratuitos? ¿oposiciones restringidas? ¿cuerpo único de enseñantes? [...] podríamos seguir formulando preguntas [...] La cuestión previa es: ¿cómo se propone una organización sindical avanzar hacia procesos de dinamización y transformación social, y qué papel cree que debe jugar en esos procesos una determinada práctica pedagógica? (p. 286).
\end{abstract}

La desesperanzada respuesta que el autor se da a si mismo - «claro que puede que no se proponga nada»— no deja de ser, en el mejor de los casos, un juego retórico que contraviene toda investigación rigurosa sobre las relaciones del sindicalismo docente con los Movimientos de Renovación Pedagógica (MRPs) desde la transición democrática, así como la dimensión central que tales asuntos ocupan en las políticas sindicales. La lectura, sin duda tediosa por intrínsecamente sindical, de investigaciones sobre la historia de algunas organizaciones sindicales de este país podría despejar sus dudas y, lo que es más importante, sus seguridades. Unas investigaciones, por cierto, muy escasas, porque (como afirma André Robert, reputado investigador del sindicalismo docente) éstas siguen normalmente la suerte del propio sindicalismo, y la debilidad de éste no favorece el auge de aquellas.

\footnotetext{
7 Jaume Martínez Bonafé, en La letra sin sangre entra. Testimonios sobre la educación en la España democrática (1978-2008), ed. Jesús Jornet (Valencia: Universidad de Valencia, 2009), 275-292.
} 


\section{DOS POLOS DE TENSIÓN EN EL SOCIETARISMO DOCENTE: MAESTROS VERSUS PROFESORES; ASOCIACIONES VERSUS SINDICATOS}

Conviene precisar, de entrada, que los docentes — término que remite a una objetiva e innegable identidad profesional sociohistóricamente construidano son «unos», no constituyen la unidad armónica y homogénea que sugiere el título de nuestro estudio. Es más, para el asunto que nos ocupa conforman un abigarrado conglomerado de titulaciones, cuerpos, escalas, estatus y situaciones laborales no sólo diversas entre si, sino objetivamente enfrentados y en disputa por las competencias y por los recursos, especialmente desde que, hace aproximadamente un siglo (cuando se constituyeron social y simbólicamente las principales profesiones «enseñantes») se consolidase su dependencia y encuadramiento dentro del Estado, fuente, paradójicamente, de su identidad como grupo profesional.

Será precisamente este encuadramiento el que determine el margen de juego en que se van a desarrollar y desenvolver sus asociaciones profesionales y el marco en el que vamos a insertar nuestro análisis; a saber: que si las profesiones se pueden entender como formas históricas de agrupación de actores para la defensa de sus intereses a través del control de su mercado de trabajo y de la representación y reconocimiento públicos de su función especializada, es cierto también que sus asociaciones profesionales (destinadas a reafirmar e institucionalizar la conciencia de grupo profesional, la defensa y salvaguarda de sus intereses económicos, el control de las formas y valoraciones ideológicas del trabajo profesional y la representación y el autogobierno del propio grupo) van a reflejar, inevitablemente, las tensiones y las controversias internas de los diferentes «rangos» de los grupos implicados, generando dinámicas internas que propendan hacia la integración pero, probablemente con la misma intensidad, también hacia el fraccionamiento.

Una de las más persistentes fuentes de segmentación de «los docentes» dentro de la tradición asociacionista (y que, de hecho, aparece ya en su misma génesis) procede de la muy particular y específica identidad profesional del maestro, determinada a su vez por el papel históricamente atribuido a la escuela - el lugar de un saber elemental no integrado formal y curricularmente dentro del sistema educativo, y ajeno, por tanto, al concierto de los saberes cultos y sus estructuras orgánicas de transmisión- que le ubica 
en una marginal condición profesional respecto al resto de docentes. Lo cual explica que los maestros y los «profesores» hayan construido históricamente dos «culturas sindicales» diferenciadas (aun cuando ocasionalmente convivan dentro de una misma organización), ${ }^{8}$ resultado de una jerarquía estructural que confirman todos los estudios comparativos: «desde su fundación en el siglo XIX, los sistemas educativos europeos han contribuido a forjar culturas profesionales y organizacionales diferenciadas, (re)produciendo estratificaciones corporativas, principalmente entre enseñantes de los sectores primario (maestros) y secundario (profesores)». ${ }^{9}$

Una segmentación de naturaleza similar se produciría dentro de colectivos que, trabajando en el ámbito de la escuela, irían desgajándose e independizándose del mundo escolar al hilo de la progresiva conformación del saber experto (profesorado normalista, inspectores de primera enseñanza, directores escolares...) que terminaría escindiéndose, como un «saber académico», del «saber práctico» de la escuela, negando, al hacerlo, (como recuerda Agustín Escolano) el estatuto no ya de ciencia, sino incluso de saber, al acervo de la experiencia práctica del maestro desde las nuevas reglas de verdad de la pretendida «ciencia de la educación» de orientación positivista; lo cual contribuyó, ya desde finales del siglo XIX, a depreciar aún más el «oficio de maestro» (y con ello su estatus social y laboral), favoreciendo el auge de estructuras asociativas propias en las que amparar las necesidades y la identidad de la clase.

Los efectos de esta escisión y prelación no pasaron desapercibidos ya en su mismo origen a quienes se ubicaban entonces en la «frontera», caso

\footnotetext{
${ }^{8}$ Joaquim Pintassilgo, en su trabajo «Associativismo docente e construção da profissão nas priméiras décadas do século XX. O exemplo dos profesores do ensino liceal», caracteriza al societarismo del profesorado de secundaria portugués como propio de un grupo poco numeroso, que enseña a una élite y adquiere por ello un cierto prestigio social, sin que ello guarde correspondencia con su escasa remuneración; por eso su asociacionismo, mas tardío que el del magisterio, estará distante del sindicalismo, al que juzgan escasamente compatible con su estatuto de profesionales; sus asociaciones prefieren presentarse como lugar de reflexión sobre el oficio y como grupo de presión sobre el poder; se consideran detentadores de un saber especializado y desenvuelven representaciones sobre el ideal de servicio que los moviliza, aunque a veces recusen su estatuto de funcionarios; véase el Quaderni de la revista Ricerche Pedagogiche, 32 (2009): 17-30, titulado La formazione docente tra attualità e storia y coordinado por Giovanni Genovesi; véase también de Joquim Pintassigo, "Os primordos do associativismo docente do ensino liceal portugues (1904-1908). As representações dos professores sobre a profissão e construção de identidades», Cuadernos de Historia da Educação, 2 (2003): 15-25; y el trabajo de Jacques Girault, Instituteurs, professeurs, une culture syndicale dans la société française (fin XIX-XX siècle) (Paris: Publications de la Sorbonne, 1996).
}

${ }^{9}$ Frajerman et al., «Les syndicalismes enseignants», 52 
del maestro Gregorio Herráiz, después profesor normalista y director de «una revista de primera enseñanza, órgano de las Conferencias y de la Asociación del Magisterio» de Valladolid; en su crítica «en caliente» a la nueva regulación que en 1887 se dio a las Conferencias Pedagógicas —el espacio societario tradicional del magisterio- vemos su nítida intuición sobre el hondo foso que entonces se abría entre el hacer, y el discurso sobre el hacer, reflejada en plásticas observaciones sobre las que vamos a detenernos.

El asociacionismo magisterial anterior a 1880 entrecruzaba actuaciones típicamente mutualistas ${ }^{10}$ con actividades regulares de autoformación -las Conferencias Pedagógicas-, organizadas por las «Academias de maestros de primera educación» entre 1840 y 1853 , y por grupos de maestros reunidos en Conversas y Asambleas tras esa fecha; entendidas como "plática entre dos o más personas que dilucidan algún asunto», su reexposición en los periódicos profesionales aparecía normalmente trufada con reivindicaciones magisteriales de diversa naturaleza, dando cuerpo, en su conjunto, a la dinámica societaria. Una situación que vino a trastornar la nueva modalidad de «formación» que articulan las Conferencias, según Herráiz, porque expropiaba el saber del oficio - construido en común y colectivamente mediante la conversa- de sus propios ejercientes al atribuir su «enunciado» a quienes dominan la confección del discurso (la «lucubración»), remitiendo a una especie de silencio operativo (más propio de obreros: y así se comenzarán a manifestar ante el hecho asociativo) a quienes sólo sabían de la práctica.

Afirma Herráiz que, si hasta entonces, en reuniones voluntarias, «de manera familiar y sencillamente, sin más auditorio que los miembros de la clase», los maestros trataban en sus conversas de "aritméticos problemas, análisis de párrafos en concepto gramatical», «lecciones sobre materia agrícola, religiosa y geográfica», puntos «relativos a la educación, la didáctica o el organismo escolar», "todo en la forma apropiada para educar y enseñar a la niñez», ahora la Conferencias — condensadas en «temas» que habían de «dilucidarse ante auditorio profesional»— excluían, si no formal-

\footnotetext{
${ }^{10}$ Hasta la década de los ochenta se toleran las formas «inofensivas» de asociación (socorros mutuos, beneficencia y cultura e instrucción) y se reprimen aquellas sospechosas de alterar el orden vigente. La R. O. de 28 de febrero de 1839 avalaba un modelo exclusivo de asociación, la de socorros mutuos, agrupaciones en que cada socio pagaba una cuota que le daba derecho a recibir unas prestaciones en caso de necesidad; véase: Fernando López Castellano, «Una sociedad "de cambio y no de beneficencia". El asociacionismo en la España liberal», CIRIEC-España, Revista de Economía Publica, Social y Cooperativa, 44 (2003): 199-228.
} 
mente, si realmente, a los maestros, cuyo saber no se organizaba en «temas», sino que enfrentaba los problemas del aula:

dilucidar en forma gráfica, tangible y fielmente ajustada a la realidad sobre el mejor método, procedimiento o útil didáctico; sobre el más hacedero y prudente método de educar esta u otra facultad o función; sobre los recursos más llanos y eficaces en el auxilio en la enseñanza encaminada a la buena instrucción, sobre infinidad de particularidades pedagógicas,

tratado todo «con confianza y llaneza propia de comprofesores, que se aleccionan recíprocamente, que aumentan y depuran su idoneidad, al paso que extienden y estrechan los vínculos del compañerismo, el espíritu de la clase». ${ }^{11}$ Cierto que podrían los maestros «invitados a ello» desarrollar los «temas», pero sólo obligándose a impostar su condición; y no sólo porque «la presencia de personalidades tan respetables para los maestros como los individuos del Claustro de las Normales y el Inspector [...] el gobernador civil o algunos vocales de la Junta de Instrucción Pública, bastarían para que los actuantes se esforzaran, no en aparecer ajustados a la prístina naturaleza de las tareas, sí a la altura de las circunstancias», sino porque su encomienda, de hacerlo, se reducía, literalmente, a «dar forma a una lucubración»:

Consultará, al efecto, no al acopio de sus observaciones en la escuela, ni tampoco a lo posible y beneficioso en el ejercicio de la educación y la enseñanza; sí a las publicaciones de más alto vuelo, siquiera muy deficientes en verdadera aplicación; expondrá y encomiará lo que ni habrá utilizado ni utilizará en su labor profesional; bordará y floreará su prehecho y preestudiado discurso, en busca de aplausos más bien que en provecho positivo de la cultura de la niñez. No otra cosa harán los objetantes, los demás que tengan su papel en la controversia; esta brillará por su ausencia o inexistencia; a un discurso seguirán otros o seguirán varios, acaso parecidos, cual si se les hubiera cortado por el mismo patrón; quizá desacorden, sin que por ello se controvierta y dilucide [...] y las piezas oratorias [...] lejos de correlacionarse, harán resaltar su mutua independencia. ${ }^{12}$

Retomamos el hilo de nuestro análisis, tras este largo excurso, para referirnos al segundo "polo de tensión» referido, condicionado, como el

\footnotetext{
${ }^{11}$ Gregorio Herráiz, Tratado de Antropología y Pedagogía, (Madrid: Librería de la Viuda de H. Hernando, 1896), 540.

12 Herráiz, Tratado de Antropología, 535.
} 
anterior, por el nicho en que se conformó la profesión docente y en el que la asociación corporativa constituía (en el período de entresiglos) el modelo organizativo predominante entre los sectores profesionales. Al igual que lo hace el corporativismo burocrático en su conjunto, también el docente presentará la profesión como «servicio» de un bien público a proteger por el Estado (de ahí la exigencia de funcionarización), haciendo de la unidad de la clase que lo ejerce (un concepto clave de la moral corporativa: su palabra mito, contrapuesta a la real fragmentación del grupo, nos recuerda Villacorta), y de la asociación que lo porta, un idealizado emblema, aun cuando, en la práctica, la mitificada unidad quede diluida ante el mínimo matiz diferencial derivado de las categorías burocráticas. ${ }^{13}$ Los fenómenos de «oligarquización» y "proletarización» que se producen dentro de la clase (entre el magisterio y el resto de los niveles de profesorado, pero también dentro de cada nivel) trituran los (supuestos) intereses "colectivos», induciendo a los subgrupos, bien a buscar una representación específica en los órganos de dirección de las asociaciones «unitarias», bien a crear asociaciones alternativas, que en ocasiones se plantean ligadas a los sindicatos de trabajadores (a partir de la década de los veinte) con los que, sin embargo, el asociacionismo corporativo diferirá sustancialmente. Porque frente a la esencia de estos - la solidaridad de clase, la lucha contra el capital- para las asociaciones corporativas es la «sociedad» en general y su representación jurídico-política, el Estado, el sujeto a interpelar; y así lo practicarán incluso aquellas que, integradas en los sindicatos, utilicen la fuerza simbólica de las organizaciones obreras a las que se asocian pero evitando expresamente la identificación entre un sindicalismo de clase y la «mera» sindicación gremial.

Los estudios comparativos a escala europea constatan, precisamente, la sindicalización progresiva, a lo largo del siglo XX, de las asociaciones profesionales docentes nacidas en sus inicios. Así lo ha documentado Frajerman

\footnotetext{
${ }^{13}$ Un mito que el autor ha datado en otro trabajo: Francisco Villacorta, «El profesorado de segunda enseñanza, 1857-1936. Estructuras, carrera profesional y acción colectiva», en Aulas con memoria. Ciencia, educación y patrimonio en los institutos históricos de Madrid (1837-1936), eds. Leoncio López-Ocón, Santiago Aragón y Mario Pedrezuela (Madrid: CEIMES, CSIC y Comunidad de Madrid, 2012), 245-264, relacionando las múltiples organizaciones de profesorado de secundaria existentes; así, durante el período republicano «la antigua Asociación de Doctores y licenciados Catedráticos de Instituto, la nueva Asociación de profesores de los Institutos Nacionales, la Asociación Profesional de Licenciados y Doctores (incorporada a la FETE), la de profesores de los Institutos locales, la de Profesores de dibujo, la de Profesores Auxiliares de los Institutos, la de profesores Ayudantes y alguna otra» (p. 259).
} 
para Francia, ${ }^{14}$ probando la progresiva transformación en sindicatos de la mayor parte de las asociaciones profesionales, aún cuando quepa preguntarse si lo hicieron o no "conforme al modelo obrero", es decir, como "verdaderos sindicatos». En todo caso, el proceso -iniciado por las asociaciones del magisterio y seguido por las del resto de los niveles educativos a lo largo de los años veinte y treinta- resultó imparable en las décadas siguientes, de manera que si durante el período de entreguerras el sindicalismo docente constituía aún una novedad rodeada de un cierto halo subversivo, tras la aprobación del Estatuto de la Función Pública en 1946 (en España lo haría ¡en 1998!) los sindicatos pasarán a desempeñar ya un rol plenamente oficial, «transitando de la sumisión a la administración a la participación con ella»: ${ }^{15}$ provistos de un quasi monopolio de representación, pasarán a integrarse dentro de las instancias de decisión en calidad no de consultores sino de corresponsables reconocidos por el Estado, y a revertir a la propia organización sindical la «gestión de las tensiones profesionales» (las posiciones ante las reformas escolares, la carrera docente, etc.).

El análisis comparativo refleja todavía otra constante con interés para nuestro análisis, derivada, en este caso, de los procesos de masificación y unificación que se produjeron dentro de los sistemas educativos a partir de los años sesenta en toda Europa, lo que comportó la correspondiente unificación de las identidades profesionales de los docentes, «más necesaria y más dolorosa en la segunda enseñanza». El consiguiente retroceso del elitismo y una mayor percepción de su estatuto de asalariados explicaría, en buena parte, el aludido fenómeno de sindicalización de las organizaciones profesionales docentes, aún cuando mantengan su huella en la preferencia, como hemos dicho, por la negociación con los poderes públicos en caso de conflicto y por los «métodos de acción globalmente moderados», recurriendo sólo excepcionalmente a movilizaciones y huelgas. Este es un aspecto, sin embargo, en el que el sindicalismo docente presenta grandes diferencias

\footnotetext{
${ }^{14}$ Laurent Frajerman, «Syndicalisation et professionnalisation des associations professionnelles enseignantes entre 1918 et 1960», en Syndicats et associations ¿concurrence ou complémentarité?, dirs. Danielle Tartakowsky y Françoise Tètard (Rennes: Presses Universitaires, 2006), 97-106. El autor establece una secuencia cronológica de dicha transformación (relativa a Francia, pero probablemente generalizable), iniciada por el profesorado de primaria más próximo al mutualismo, afiliando confederalmente sus asociaciones profesionales a sindicatos de trabajadores, aun cuando siguiesen manteniendo internamente aquellas tradiciones. La sindicación de las asociaciones profesionales del resto de los niveles prosigue esta misma dinámica, transformándose en sindicatos autónomos para, posteriormente, proceder a su adhesión a los sindicatos obreros.
}

${ }^{15}$ En Frajerman, http://histoire-sociale.univ-paris1.fr/Collo/frajerman.pdf, p.4 
inter-países, al igual que ocurre en lo relativo a su estructura organizativa interna, "dominio donde la cultura nacional y las especificidades internas de cada organización se expresan plenamente». En todo caso, Frajerman insiste en las concomitancias entre fines y medios de ambas modalidades organizativas (asociaciones y sindicatos) suscribiendo la valoración que yo misma había expresado para el caso español, localizando sus diferencias más en los discursos que en las funciones objetivamente desempeñadas. ${ }^{16}$

\section{EL DESARROLLO DEL ASOCIACIONISMO DOCENTE EN ESPAÑA ${ }^{17}$}

La síntesis que presentamos a continuación tiene dos limitaciones importantes. Con excepción de aquellas monográficas y de publicación reciente, no se incluyen la mayor parte de las referencias bibliográficas sobre las que se apoya. Y tampoco se mantiene una homogeneidad en el tratamiento otorgado, en cada periodo, a precisar la interrelación entre dinámicas societarias y sindicales y políticas educativas, lo cual resulta particularmente insuficiente en el apartado sobre «el período democrático».

\section{Primer tercio del siglo $\mathrm{XX}$}

Un significativo ejemplo de la intersección entre la dinámica organizativa del profesorado (sea en forma de asociacionismo profesional o como neto sindicalismo) y las políticas concretas que orientaron la evolución de nuestro sistema educativo, lo encontramos, precisamente, a principios del siglo XX. Es entonces (agosto de 1901) cuando un disgregado y desorganizado magisterio consigue traducir sus débiles conatos organizativos de ámbito local en una potente Asociación Nacional del Magisterio Primario, de carácter estatal y con una estructura federada, cuya reivindicación aglutinante será la financiación de la enseñanza primaria por el Estado, incorporando sus haberes (dependientes hasta entonces de los ayuntamientos y de las retribuciones de los alumnos) a los presupuestos del Es-

\footnotetext{
${ }^{16}$ En ello coincide también Antonio Guerrero Serón, «¿Por qué el profesorado no se sindica?», Educación y Sociedad, 7 (1990): 29-52, afirmando que «ello conlleva el que sindicatos y asociaciones aproximen bastante sus plataformas reivindicativas hasta parecerse enormemente: los de clase con reivindicaciones profesionales y los corporativos con otras tantas sindicales» (p. 52).

${ }^{17}$ Un desarrollo intrínsecamente interrelacionado con el del propio sistema educativo; imposible de abordar aquí, remitimos al trabajo de Antonio Viñao, Escuela para todos. Educación y modernidad en la España del siglo XX (Madrid: Marcial Pons, 2004).
} 
tado. ${ }^{18}$ Su conquista supuso un hito histórico en la consolidación de la primera enseñanza (que se hizo gratuita para los alumnos) y del magisterio como cuerpo de funcionarios del Estado, si bien siguiese manteniendo un criterio de subsidiariedad respecto a la creación de escuelas, siendo entes diversos (ayuntamientos, entidades privadas, principalmente religiosas, y benefactores particulares) quienes discrecionalmente «ponían y quitaban» escuelas.

La Asociación Nacional del Magisterio, fortalecida en los años siguientes con organizaciones locales y provinciales en prácticamente todas las provincias y con una afiliación que en 1911 se cifraba en unos 15.000 maestros y maestras (aproximadamente la mitad de los maestros públicos existentes), crecida por la conquista del mencionado objetivo unitario y capaz de poner en el escenario público el candente tema de la educación y de su insuficiente desarrollo (reclamando una más decidida intervención del Estado ante la inerme «educación nacional»), irá articulando nuevas plataformas reivindicativas en las que, junto con componentes de tipo pedagógico, la conquista de un «sueldo mínimo» para el magisterio se plantea irrenunciable.

Esa unidad, sin embargo, será rota por la estrategia del ministerio de rechazar ese mínimo exigido y proponer la ordenación de los sueldos de los maestros en un Escalafón estructurado en un amplio abanico de escalas salariales, con un porcentaje mínimo de plazas en las primeras categorías. Los colocados en las últimas (más del $80 \%$ ) y aquellos insertos en la condición administrativa de «derechos limitados» (interinos, fundamentalmente) terminarán por escindirse de la Nacional y crear sus propias asociaciones, mientras que otros, en un número todavía muy reducido y desde otro tipo

\footnotetext{
${ }^{18}$ Recordamos que la prensa profesional jugó un papel fundamental en el asociacionismo del magisterio, rompiendo su tradicional aislamiento geográfico y sociológico, que dificultaba el surgimiento de una práctica y una mentalidad colectivas. A través de ella se irán perfilando las «reformas que son indispensables para el verdadero mejoramiento de la primera enseñanza y para el prestigio y la consideración que se debe al magisterio». Tales eran: el pago de la primera enseñanza por el Estado, rompiendo los «funestos lazos que la encadenan a los ayuntamientos», la eliminación de las retribuciones al maestro por parte de los alumnos sustituyéndolas por compensaciones en el sueldo, la nivelación del sueldo entre maestros y maestras, el reconocimiento de derechos pasivos y la restricción del ejercicio de la profesión mediante la exigencia de titulación para abrir establecimientos de enseñanza; además, el incremento del numero de escuelas, incluyendo las de párvulos, el ingreso mediante oposición, la libertad en la elección de los libros de texto, la obligatoria posesión del certificado de escolaridad, y la creación del Ministerio de Instrucción Pública. Véase Aida Terrón, «Cien años de defensa colectiva: la dinámica societaria y sindical del magisterio español», Sarmiento, 3 (1999): 157-182 (citas en p. 162), así como «El movimiento asociacionista del magisterio nacional. Orígenes y configuración histórica», Historia de la Educación, 6 (1987): 279-299.
} 
de consideraciones, entenderán que enfrentarse a las maniobras divisorias y distractoras del ministerio exigía una opción sindical de clase, abandonando el asociacionismo profesional y adoptando como horizonte la lucha de la clase trabajadora tanto en sus programas políticos como en sus estructuras sindicales y métodos de lucha.

Invitando al maestro a «ir a la Casa del Pueblo y a la Unión General de Trabajadores, porque del pueblo somos y para él trabajamos», y a abandonar los gastados mecanismos de presión (como las campañas de prensa o la búsqueda de apoyos entre diputados), sustituyéndolos por la huelga (el instrumento de presión por excelencia), en la segunda década de siglo comenzarán a surgir los primeros conatos de maestros organizados en la Unión General de Trabajadores (UGT): en 1912 aparece la Asociación General de Maestros (AGM), de orientación socialista, reapareciendo en 1919, cuando la revolución soviética estaba favoreciendo el sindicalismo de clase entre los docentes europeos. En ese mismo año la AGM se integrará en la Internacional de Trabajadores de la Enseñanza y desde entonces el sindicalismo docente socialista, con escasa presencia cuantitativa y poca capacidad de presión ante el ministerio (entre otras razones porque en 1918 se prohíbe a los funcionarios la pertenencia a sindicatos, decisión reiterada durante la dictadura de Primo de Rivera), irá incorporando un prestigioso profesorado (muchos de ellos inspectores, profesores normalistas y de Universidad) que contribuirá a definir la dimensión sindical de la alternativa escolar socialista que se desarrolla en el período republicano.

El asociacionismo profesional (la Asociación Nacional del Magisterio y aquellas escindidas de la misma) conseguirá reunificarse en la década de 1920 buscando un objetivo aglutinador en las reivindicaciones salariales: la presión por la modificación del Escalafón, que había introducido el enfrentamiento interno, fue sustituida por la exigencia de «equiparación salarial del magisterio con los sueldos de los demás funcionarios del Estado, con las categorías que ellos tienen y en la misma proporcionalidad», objetivo que va a marcar en el futuro el horizonte de las luchas.

Las plataformas reivindicativas que tanto el asociacionismo profesional como el inicial sindicalismo socialista irán perfilando durante todo este período, condicionan (con más o menos fuerza, pero marcando línea) la política educativa que el ministerio va a modular durante las tres primeras décadas de siglo, «empujando» una efectiva modernización educativa que implicaba (tal como recogen dichas plataformas) 
la concepción del sistema educativo como servicio público nacional, centralizado y bajo la dependencia exclusiva del Estado tanto desde el punto de vista de la gestión como del financiero, exigiendo eliminar las subvenciones a las escuelas privadas (incluso las municipales) mientras no existiesen las públicas suficientes; financiación estatal de locales, material, casa-habitación para el magisterio, etc.; obligatoriedad de la asistencia escolar creando las escuelas necesarias; regulación de la profesión como una carrera docente que incluyese al magisterio primario, las Normales, la Inspección, las Secciones administrativas de Instrucción Pública y hasta una Facultad de Pedagogía cuya creación se solicitaba por estos años. ${ }^{19}$

Un horizonte de reformas que los gobiernos republicanos habrán de retomar, pero que adquiere su primera manifestación en un Estatuto del Magisterio (1917) que codificará el cuerpo y la profesión del magisterio como funcionario del Estado.

En los años inmediatamente anteriores a la República, y a pesar de sus diferencias, el asociacionismo profesional y el sindicalismo de clase comparten una intensa preocupación por lo que podríamos denominar la dimensión pedagógica de la escuela, implicando a sus afiliados en la búsqueda de una metodología docente transformadora, «neutra» en el caso del asociacionismo profesional, y «sociopolítica» en el del sindicalismo sociopolítico, que, influido por la orientación bolchevique del sindicalismo internacional, subraya el carácter de clase de la escuela, proponiendo el modelo ideológico-organizativo de «escuela única del trabajo» o «escuela proletaria».

En cuanto al profesorado de otros niveles, siguen escaseando los trabajos que dibujen un trazo general sobre su «acción colectiva» durante esas décadas, si bien los existentes confirman su distancia respecto del magisterio. Villacorta sostiene que el modelo profesional y el incentivo corporativo que movía las acciones organizativas y reivindicativas del profesorado de secundaria seguían miméticamente el de su «hermano mayor, el profesorado

\footnotetext{
19 Terrón, «Cien años de defensa colectiva», 167. En el XVI Congreso de la UGT, 1920, se aprueban como exigencias básicas la enseñanza obligatoria y gratuita en todos sus grados, la creación de las escuelas necesarias, la equiparación económica con el resto de los funcionarios y la unificación en la preparación y remuneración del personal docente. El decálogo que inspira la Constitución republicana, recogiendo los planteamientos aprobados en los Congresos del PSOE de 1918 y 1931, decía sobre este último punto: «El profesorado, en todos sus grados, recibirá una preparación equivalente, desempeñará un trabajo equiparable y será objeto de análoga remuneración».
} 
universitario ${ }^{20}$ con el que compartía una misma reglamentación de su vida burocrática desde 1857. Sus primeras asociaciones — de profesores auxiliares de instituto, y de catedráticos de instituto, con sus respectivos órganos de prensa- se formaron en 1893, si bien fue el sistema colegial, que los hermanaba "con otros grupos profesionales de mayor rango y tradición", el modelo preferido. El primer Colegio de Doctores y Licenciados en Ciencias y en Letras se creó en Madrid en 1899, seguido por otros, obligatorios en todas las capitales de distrito universitario desde 1906. La lucha contra el intrusismo —especialmente de la enseñanza privada confesional- fue el detonante de su acción colectiva en los primeros años de siglo, siempre fragmentada, sin embargo, por la estructura escalafonada del cuerpo y su amplio abanico salarial: como afirma Villacorta significativamente, «el presupuesto vino a poner las cosas en su sitio» en relación con la unidad entonces y durante el periodo de activísima vida corporativa que desencadenó entre los grupos profesionales el «sueño» republicano, "pronto reducido(s) a los términos de la cruda realidad económica del momento». ${ }^{21}$

\section{La II República y la guerra civil}

La relación de la II República con unas organizaciones fuertes (la Asociación Nacional del Magisterio, 20.000 afiliados; la Confederación Nacional de Maestros, que representaba básicamente a los interinos, 7.000; y la Federación Nacional de Trabajadores de la Enseñanza (FETE) —nombre que desde 1932 recibirá la antigua Unión General de Maestros-, 1.500) es ambivalente. Su programa de reformas, ${ }^{22}$ hostilmente combatido por la Iglesia católica, contaba inicialmente con la adhesión del profesorado, a cuyas organizaciones llamó a colaborar; pero si bien el plan quinquenal de creación de escuelas y el

\footnotetext{
${ }^{20}$ Villacorta, «El profesorado de segunda enseñanza», 246.

${ }^{21}$ Villacorta, «El profesorado de segunda enseñanza», 259.

${ }^{22}$ En la dirección del Ministerio de Instrucción Pública (MIP) están ahora hombres que provienen del sindicalismo docente socialista y defienden una reforma educativa inspirada en el modelo de «escuela única o unificada»: incorporado al articulado constitucional, este modelo implicaba al Estado en la actividad social, económica y cultural de la nación, garantizando el derecho a la educación, al que queda subordinada "la riqueza del país, sea quien fuere su dueño», "con expropiación forzosa en caso de necesidad». Por ello el «servicio de la cultura» se entiende como una «atribución esencial del Estado», que queda obligado a prestar en «instituciones educativas enlazadas por el sistema de escuela unificada», suprimiendo la autorización docente a las órdenes y congregaciones religiosas (que no a sus miembros en cuanto particulares). Declara, igualmente, la obligatoriedad y la gratuidad de la enseñanza primaria, y establece el mandato de legislar para facilitar a los económicamente necesitados el acceso a todos los grados de la enseñanza de acuerdo con su aptitud y vocación.
} 
significativo incremento salarial de las últimas categorías del Escalafón (en el que consiguen integrarse también los maestros interinos) fueron conquistas saludadas como tales, las discrepancias van a surgir inmediatamente. La FETE, con un espectacular crecimiento, no logrará evitar las tensiones internas provocadas por el incumplimiento de algunas expectativas, especialmente la homologación con el resto de los funcionarios del Estado.

Algunas opciones ideológicas presentes en su seno criticarán radicalmente otras dimensiones de la labor ministerial. Lo harán aquellos militantes (particularmente los comunistas) que sigan las consignas de la Internacional de Trabajadores de la Enseñanza (ITE) —integrada, a su vez, en la Internacional Sindical Roja- a la que pertenecía la FETE. Estos sectores más radicales, frente a los más proclives al reformismo educativo (representado por otra potente organización internacional, nacida en 1926, el Secretariado Profesional Internacional de la Enseñanza (SPIE), con la que se identificaban más los dirigentes socialistas republicanos), constatarán no sólo las insuficiencias y los incumplimientos del plan quinquenal de creación y de construcción de escuelas, sino también la timidez en la aplicación del laicismo escolar, el fracaso en la sustitución de las órdenes religiosas dedicadas a la enseñanza y, en definitiva, del modelo de «escuela única». Plantean «buscar una relación más estrecha con las masas trabajadoras y campesinas», ahondando en el sindicalismo de clase y acusando a la vieja guardia-militantes históricos del Partido Socialista Obrero Español (PSOE), de tendencias reformistas y ligados a la Institución Libre de Enseñanza, ubicados en los puestos clave de la administración educativa- de reformismo, colaboracionismo y desviacionismo ideológico. En el Congreso extraordinario de la FETE de 1934 estos sectores se harán con la dirección del sindicato, dispuestos a politizarlo en un momento en que no cabía sustraerse a la opción fascismo o revolución (afirman) trabajando en la puesta en marcha de un Frente Único de trabajadores de la enseñanza, que adopte «nuevos métodos de lucha» en coordinación con el resto de los trabajadores. ${ }^{23}$

El Frente Único consigue articularse formalmente ese mismo año, en un momento de ofensiva de las fuerzas conservadoras y de rearme de la Iglesia católica, que crea organizaciones nuevas como la Federación de Amigos de la

\footnotetext{
23 Así titulaba uno de sus artículos el asturiano Cesar García Lombardía, que se hará en ese Congreso con la Secretaría de la FETE, siendo significativo que, el mismo día en que el Congreso se clausure, Lombardía sea detenido, junto con otros miembros del sindicato, en una concentración de maestros ante el ministerio, la primera, probablemente, realizada por el colectivo.
} 
Enseñanza o fortalece otras como la Federación de Maestros Católicos; pero las discrepancias internas ante asuntos centrales como la distinta posición sobre la exigencia de la sustitución de las órdenes religiosas — reclamada por la FETE pero no bien vista por otras organizaciones-, o la distribución de los fondos para incremento de sueldos dentro de las distintas categorías del Escalafón, lo harán escasamente efectivo. Ese mismo año se producen otros retrocesos significativos en la vida sindical que vendrían justificados por la implicación de maestros asturianos en la revolución del 34: la prohibición gubernativa de la revista de la FETE Trabajadores de la Enseñanza, que reaparecerá bajo el gobierno del Frente Popular en 1936, es uno de ellos. En este nuevo y convulso marco político, la Asociación Nacional del Magisterio se integrará en la FETE, que se convierte en una potentísima organización que disputa su espacio a otra, activada por la situación bélica inminente; nos referimos al Sindicato Único de Enseñanza, ligado a la anarquista Confederación Nacional del Trabajo: limitado a algunos territorios, su fortísima implantación en Cataluña (más de 9.000 afiliados) le permitirá actuar como un auténtico elemento de control del ámbito cultural durante la contienda civil. Ambos sindicatos frentepopulistas se implicarán entonces no solo en la labor de gestión y administración del servicio educativo, sino también en solucionar las necesidades de la guerra (evacuación de niños, colonias escolares, alfabetización en el frente, batallones de profesorado, etc).

\section{El Régimen franquista y la transición a la democracia}

El «atroz desmoche» con que se saldó el proceso de depuración de los cuerpos de profesores tras la guerra civil, considerados como enemigos peligrosos tanto más cuanto que no se les podía desarmar como si de un ejército regular se tratase, fue eficaz tanto por el número de profesores separados definitivamente de sus plazas, desterrados o inhabilitados para el desempeño de cargos, como, sobre todo, por el régimen de terror en que se produjo. Acusaciones anónimas sobre la conducta no solo política o sindical, sino también profesional e incluso familiar o privada de los profesores (no estar casado por la iglesia, blasfemar...) tuvieron, por sus terribles consecuencias individuales, el efecto de amedrentar y retraer al colectivo, decapitándose de esta manera el sector más activo y dinámico del profesorado. Suprimido el pluralismo político y sindical, el franquismo decretó el encuadramiento obligatorio de todos los trabajadores en sindicatos verticales estructurados por ramas de producción, haciéndolo los maestros 
en el Servicio Español del Magisterio (SEM), en el SEPEM los profesores de enseñanza media, en el SEPET los de enseñanzas técnicas y en el SEPES los de enseñanza superior - los estudiantes universitarios habrían de hacerlo en el Sindicato Español Universitario (SEU)—. Se trata de organizaciones destinadas en exclusiva a mantener fidelizado, catolizado y paralizado al colectivo, como correspondía a un inequívoco «tiempo de silencio».

Y sin embargo, el «movimiento» echó a andar. Las primeras acciones de protesta estudiantil universitaria (años 1954 y 1956, contra la afiliación obligatoria al SEU) se produjeron de manera casi sincrónica con la primera «comisión obrera», una comisión espontánea de trabajadores que convocan y gestionan la huelga minera de la Camocha (Asturias) en 1957. Era el inicio de los movimientos estudiantil y obrero, respectivamente, que «agitarían» otros movimientos en los años siguientes, y que conseguirían dotarse de estructuración orgánica ya en la década de 1960. Para entonces los universitarios habían logrado articular una organización estudiantil clandestina (la Federación Universitaria de Estudiantes y, posteriormente, el Sindicato Democrático de Estudiantes) cuyo aglutinante seguía siendo el rechazo al monopolio del SEU pero también a la creciente influencia del Opus Dei en la Universidad pública, tras haber sido autorizado previamente a expedir titulaciones oficiales en la suya propia.

En los años siguientes estos nacientes movimientos (estudiantil y obrero, con participación de profesores universitarios en el primer caso) profundizarán su dimensión política de oposición al Régimen, intentando forzar la penetración de sus miembros (adheridos a organizaciones políticas clandestinas: socialistas, comunistas, cristiano-progresistas y nacionalistas) en la única estructura sindical entonces legal, los «sindicatos verticales». La constitución en Madrid, en 1966, de la primera coordinadora estatal de Comisiones Obreras (CCOO) mostraba ya la consolidación organizativa de un sindicalismo que, aunque clandestino, había conseguido dar el salto desde unas «comisiones» provisionales, creadas para la resolución de conflictos concretos, a una organización permanente y estructurada. Su ideario y propuestas se plasmarían en el manifiesto titulado «Ante el futuro del sindicalismo», presentado por primera vez (fuera de las asambleas de trabajadores y los centros de trabajo) en diciembre de 1965 en el Club de Amigos de la UNESCO de Madrid. ${ }^{24}$ Los datos sobre la conflictividad laboral en esa década muestran un «antes y un después» de esta consolidación sindi-

${ }^{24}$ Antonio Gómez, Tantas vidas, tantas luchas. Club de Amigos de la UNESCO de Madrid, 1961-2001 (Madrid: CAUM: 2012). 
cal: si en 1962 el 87\% de los conflictos respondían a razones estrictamente económicas, y solo un $11 \%$ a protestas por solidaridad o por despido de algún compañero, en 1967 predominarán las motivaciones políticas: frente a un $13 \%$ de huelgas por mejoras salariales, las organizadas por razones solidarias, esencialmente detenciones y despidos, eran ya el $31 \%$ del total. ${ }^{25}$

Por lo que hace a la organización de los docentes, su génesis durante la clandestinidad hay que buscarla en esas mismas aguas. La participación en el movimiento estudiantil nutrirá de comportamientos político-sindicales al futuro profesorado de la enseñanza secundaria y universitaria, especialmente entre quienes iban a hacerlo, bien como «Profesores No Numerarios» en ambos niveles educativos, bien como "personal contratado» en la enseñanza privada - mayoritariamente religiosa-, cuyo florecimiento durante los años de esplendor del nacional-catolicismo (originado por la inhibición de la iniciativa pública, expresamente declarada subsidiaria por el Estado franquista) se multiplicaría, curiosamente, a partir de la década de 1960, durante la llamada «fase desarrollista»: la red privada añadirá entonces a su tradicional clientela - las clases media y alta - un alumnado procedente de clases populares emigradas a las grandes ciudades industriales y carente de un puesto escolar público. Por esos mismos años se asiste a un tímido reforzamiento del papel del Estado en la enseñanza, inserto en una dinámica de racionalidad técnico-burocrática o tecnocracia economicista, siguiendo las recomendaciones de la UNESCO y de otros organismos internacionales como el Banco Mundial y la OCDE. Los gestores de esta dinámica, los ministros del Opus Dei, van a promover una política económica de estabilización primero y de desarrollo después, iniciando un proceso sustancial de reforma de un sistema educativo para entonces completamente anquilosado, ${ }^{26}$ que culminará con la Ley General de Educación (LGE) de 1970.

\footnotetext{
${ }^{25}$ Gómez, Tantas vidas, 120.

26 Ana Mari García, maestra asturiana, lo describía gráficamente: «Existían entonces dos redes educativas, separadas, paralelas, con un paralelismo que respondía a una definición que por aquel entonces venía en la Enciclopedia Álvarez y que decía «rectas paralelas son aquellas que por mucho que se prolonguen no se llegan a encontrar». Y así era con los dos sistemas existentes. la escuela nacional, primaria, gratuita, donde se permanecía teóricamente hasta los 14 años, aunque en la práctica hacia los 12 años el abandono era generalizado. La otra red empezaba con la preparación para el ingreso en el bachillerato. Ese examen constituía toda una epopeya; la primera traba selectiva que había que superar y que abría las puertas para circular por un sistema educativo autoritario, confesional, con discriminación de géneros, severísimo con los alumnos a los que consideraba imprescindible hacer sufrir, dado que ningún camino placentero conduce a buen lugar». Véase Ana Mari García, «Pasión pedagógica. Una visión particular de la historia del MCEP», en Por una escola do Povo, ed. Xosé Manuel Cid et al. (Vigo: Universidade de Vigo, 1997), 31-35.
} 
Inserto en este proceso, una parte del profesorado irá aprendiendo a enunciar, impulsar, organizar y gestionar un amplio abanico de actuaciones reivindicativas de carácter salarial, pedagógico, profesional, político y ciudadano constitutivas de esa amalgama llamada «movimiento de enseñantes», del que, en abril de 1977, declarada la libertad sindical, surgirán las organizaciones sindicales. Forzando el estrecho margen asociativo que había abierto la ley de Asociaciones de 1964 — que permitió la creación de Asociaciones de Antiguos Alumnos de Escuela Normal—, «tomando» las organizaciones corporativas legales (los Colegios de Doctores y Licenciados en Ciencias y Letras, desbancando a sus direcciones, próximas al Régimen), o copando puestos en el sindicalismo vertical mediante la táctica de presentarse a las elecciones para enlaces dentro de la enseñanza privada, los docentes más politizados desbordarán definitivamente el marco de su «encuadramiento obligatorio». Este magmático movimiento, que durante los años 1960 y 1970 fue capaz de adquirir presencia social, fuerza y experiencia suficiente para articular una(s) Alternativa (s) Democrática(s) a la Enseñanza (nutrida con las propuestas críticas a la Ley General de Educación) ${ }^{27}$ estaba a la vez indisociablemente incrustado en los espacios de compromiso y renovación pedagógica (el Movimiento Cooperativo de Educación Popular, las Escuelas de Verano, etc.) como era propio en un momento en que la ruptura política no podía pensarse sin una paralela ruptura pedagógica.

El desarrollo de sus plataformas reivindicativas condujo a la creación de estructuras unitarias para articular la acción, si bien diferenciadas por niveles educativos: ni siquiera la estrategia de intentar aglutinar (también a nivel lingüístico) las luchas sindicales de los cuerpos de licenciados y de maestros, mediante el recurso al vocablo unitario «enseñantes», pudo evitarlo. Con representantes de los centros de trabajo y sobre decisiones acordadas en las Asambleas de zona, universidad o provincia, las Coordinadoras de Maestros, las de los Profesores No Numerarios de

\footnotetext{
${ }^{27}$ La Alternativa aprobada en el Colegio de Doctores y Licenciados de Madrid en enero de 1976 recogía, en esencia, el programa del «movimiento de enseñantes»: escolaridad obligatoria y gratuita de los cuatro a los dieciséis o dieciocho años; ciclo único de enseñanza; escuela pública, laica y coeducativa; enseñanza en lengua materna; libertad de cátedra de los enseñantes; control democrático de la planificación educativa; gestión democrática y autónoma de los centros de enseñanza; igualdad de oportunidades en el acceso a la educación superior; calidad de la enseñanza; ajuste a las necesidades sociales; autonomía y responsabilidad de las Autonomías en la enseñanza; estabilidad laboral y retribuciones dignas para un cuerpo único de enseñantes, etc.
} 
Institutos de Bachillerato y las de los de Universidad, se consolidaron como estructuras de coordinación de las movilizaciones durante las huelgas de los años setenta. La llevada a cabo por el magisterio primario en 1973, exigiendo el aumento salarial comprometido en el artículo 108.4 de la LGE, seguida por más de cien mil maestros públicos y privados de toda España, va a sancionar la liquidación definitiva de la representatividad del SEM. ${ }^{28}$ El movimiento de enseñantes (que aspiraba a hacer posible un «sindicato único de docentes» solo un año después) ya no cabía en las costuras de una organización sindical que, en el ejercicio de su acción representativa, se conformaba con "ser consultada" por la administración. Tras la huelga de febrero de 1976 (la «huelga de los consortes») el ministerio se verá ya obligado a convocar — de «forma excepcional» y para gestionar las reivindicaciones que la habían motivado- unas elecciones democráticas a representantes del magisterio primario. En ellas, por primera vez tras el largo franquismo, participaron 120.000 personas que eligieron a 52 representantes (uno por provincia, más los de Ceuta y Melilla), la mayoría de los cuales venían trabajando en el ámbito de las Coordinadoras. Manuel Arango, representante de la Asturias, refiere el final de ciclo de esa estructura representativa, que

terminó su corta vida a principios de 1978 [...]; en este periodo se consiguió el complemento de dedicación plena y exclusiva para maestros, terminando con las humillantes permanencias, la jubilación forzosa a los 65 años, la igualdad retributiva para interinos y el derecho de sindicación de los funcionarios. A partir de ahí la Coordinadora desapareció y dio paso a los sindicatos de enseñanza. ${ }^{29}$

\footnotetext{
${ }^{28}$ En 1972 el presidente del SEM, Mendoza Guinea, hacía valer tanto la fuerza de su organización, que estimaba en 60.000 asociados, como su carácter plural: «El actual SEM es por su estructura, funcionamiento y finalidades, un sistema asociativo plural en el que [...] se han venido integrando las Asociaciones de catedráticos y profesores de las Escuelas Normales de Magisterio, los inspectores técnicos de educación, los directores escolares, los componentes del magisterio oficial y del magisterio privado, en fin, todos los estamentos de la educación. El funcionamiento de estas asociaciones es autónomo, mediante los correspondientes órganos colegiados elegidos por los propios asociados». Y añadía que, «con independencia de la situación actual», la sindicación debería ser obligatoria para todos los funcionarios estatales, "con todas las consecuencias que ello representa» (Servicio Español del Magisterio, El SEM y la reforma educativa (Madrid: Jefatura Nacional del SEM, 3 vols., 1972): II, 121).

${ }^{29}$ Aida Terrón, «Sistema educativo y movilización del profesorado en España: del franquismo a la transición democrática», en Educación y sindicalismo de clase. El Sindicato de Enseñanza de CCOO de Asturias (1978-2013), coord. Octavio Monserrat (Oviedo, FECCOOA 2014), 35-67 (cita en p.60).
} 


\section{El período democrático}

La decisión sobre el modelo organizativo a adoptar por el «movimiento de enseñantes» en la nueva situación de legalidad fue debatida en el curso 1976-1977, analizando la nueva estructura de sindicación a crear, así como su vinculación, directa o no, con el movimiento obrero; algo muy complejo en un momento de liquidación formal del Régimen franquista y transición hacia la democracia. Las distintas formaciones políticas, muy incrustadas en las Coordinadoras, presionaban en direcciones divergentes en relación con las dos cuestiones básicas que era preciso determinar, a saber: si la nueva organización había de decantarse por un sindicalismo de clase (como había planteado ya la Alternativa Democrática y defenderán básicamente las organizaciones de izquierda y progresistas) o por un modelo profesional de asociación colegial; y una segunda decisión relativa al carácter único o plural del marco sindical; esto es, si ir a la pluralidad de sindicatos, o bien, si hacerlo, pero en el marco de una central sindical unitaria. Una decisión que no podía sustraerse a la carrera de las organizaciones políticas por ocupar espacios y hegemonizar la dinámica sindical, condicionándola y cerrándola en una dirección muy concreta.

En sus estudios sobre la historia de la FETE (que desde 1970 había comenzado a organizar pequeñas agrupaciones provinciales) Francisco de Luis apunta a ese juego político, afirmando que «tanto el gobierno de Arias como después el de Suárez, percibieron rápidamente [...] que podía debilitarse el movimiento sindical, que en la práctica era casi equivalente a CCOO, si se ayudaba a UGT a crear un espacio propio. Por ello, mientras se continuaba persiguiendo y encarcelando a dirigentes de CCOO, se aceptaba, de hecho, a la UGT —y en consecuencia también a la FETE— al autorizar su XXX Congreso [...] en abril de $1976 »{ }^{30}$ La opción de UGT por la pluralidad sindical y su decisión de mantener la FETE, hacía inviable la opción unitaria tanto en el conjunto de la clase obrera como en los sectores «profesionales», entre ellos la enseñanza. Lo cual marcó el paso a las decisiones de CCOO, ${ }^{31}$ que llegó a modificar el acuerdo adoptado por su Secretariado Confederal en 1976 (impulsar, entre los sectores técnicos y profesionales _incluida la

\footnotetext{
${ }^{30}$ Francisco de Luis, La FETE (1939-1982). De la represión franquista a la transición democrática (Madrid: Editorial Tecnos, 2009), 232.

${ }^{31}$ Las primeras «Comisiones de Enseñanza» se habían creado en Madrid en 1968, y poco después en Andalucía, Cataluña, Valencia y Asturias, aunque desde 1962 ya seguían la táctica de las «comisiones obreras» presentándose a las elecciones como enlaces en la enseñanza privada.
} 
enseñanza- una opción autónoma y lo más unitaria posible partiendo de las Coordinadoras) para optar, solo unos meses después, por el modelo confederal, es decir, la afiliación a CCOO, poniendo en marcha la Federación de Enseñanza de CCOO en enero de 1978. ${ }^{32}$ Lo cual tuvo consecuencias sobre la situación en que hubo de moverse una tercera fuerza sindical, los Sindicatos de Trabajadores de la Enseñanza (STEs), ${ }^{33}$ que se veían como una herencia «natural» del movimiento unitario de los enseñantes y de las Coordinadoras.

Además de estos sindicatos de «clase» o progresistas, en esos mismos años se forman los profesionales o corporativos: ANPE (Asociación Nacional de Profesores de Enseñanza) y FESPE (Federación de Sindicatos de Profesores de Educación General Básica), procedentes del extinto SEM y reducidos inicialmente al magisterio primario; y CSIF, que engloba a distintos sindicatos independientes sectoriales del ámbito de la función pública. Por último, en el campo exclusivo de la enseñanza privada, aparecerán en 1978 la FSIE (Federación de Sindicatos Independientes de Enseñanza, confesional) y FESITE (Federación de Sindicatos Independientes de Trabajadores de la Enseñanza), que venía de las estructuras sindicales verticales y que en 1980 se vinculará con Unión Sindical Obrera (USO).

La relación anterior, a la que habría que añadir el sindicalismo nacionalista (ELA-STV y los fusionados en la Confederación Intersindical Galega) conformaba un mapa sindical muy dividido - que no ha experimentado grandes variaciones en los últimos cuarenta años- lo que constituye un síntoma inequívoco de debilidad. La fragmentación territorial que introdujo el «Estado de las autonomías», con diferentes ritmos de traspaso de competencias, ${ }^{34}$ añadió, además, una paralela fragmentación sindical, de-

\footnotetext{
${ }^{32}$ Una razón de peso, aunque no la única. Javier Doz, primer secretario de la Federación recuerda que los contactos con el sindicalismo europeo ideológicamente afín influyeron en ello; fue el responsable del sindicato de educación secundaria de la FEN francesa (el SNES) quien le recomendaría «optar por el sindicalismo de $\mathrm{CCOO}$, argumentando que la FEN no era ningún modelo con sus casi 30 sindicatos de sector y categoría, divididos por razones políticas y corporativas e incapaces de convocar una huelga unitaria» (Monserrat, Sindicalismo de clase, 25).

${ }^{33}$ Los STEs se transformarían en UCSTE (Unión Confederal de Sindicatos de Trabajadores de la Enseñanza) en 1978, sufriendo otros fraccionamientos posteriormente.

${ }^{34}$ Desde el momento en que las autonomías de la «vía especial» aprueban sus Estatutos (Cataluña y País Vasco en 1979, Galicia y Andalucía en 1981) recibirán transferidas las competencias educativas universitarias y no universitarias; Navarra, Canarias y Comunidad Valenciana las recibirán en 1982 y el resto («territorio MEC») en 1995-96 las universitarias y en 1998-99 las no universitarias.
} 
bilitando a unas organizaciones que no conseguirán cobrar peso en estos primeros años democráticos. Su situación se vería definitivamente apuntillada por los por los gobiernos de la Unión de Centro Democrático (UCD) de 1978 a 1982, «incapaces» de aprobar un Estatuto de la Función pública que regulase los derechos de negociación y representación sindical (y por tanto su capacidad de acción efectiva), en una sospechosa "omisión» que coincidía precisamente con el momento en que esos gobiernos sacaban adelante la primera ley educativa de la democracia (la Ley Orgánica del Estatuto de Centros Escolares, _LOECE— de 1980), ley que, tras los Acuerdos de 1979 entre el Estado y la Iglesia católica, abría el paso a la doble red escolar, posibilitaba la enseñanza de la religión católica en todo el sistema educativo, la introducción de un ideario en los centros privados concertados, y una sesgada interpretación de la Constitución en relación con la libertad de elección de centro.

Fue con el primer gobierno del PSOE cuando se desarrolló la legislación sindical (las primeras elecciones sindicales en la Función Pública, profesorado incluido, se celebrarían en diciembre de 1987) y se reguló la aportación de recursos materiales a los sindicatos (devolución de la «deuda del patrimonio sindical», regulación de las «liberaciones» sindicales, etc.); las leyes educativas socialistas — la Ley de Reforma Universitaria (LRU) de 1983, la Ley Orgánica del Derecho a la Educación (LODE) de 1985, la Ley Orgánica General del Sistema Educativo (LOGSE) de 1990, y la Ley Orgánica de la Participación, la Evaluación y el Gobierno de los Centros Educativos (LOPEGCE) de 1995- provocarían sin embargo, discrepancias y tensiones sindicales (externas y también internas) tanto por el modelo educativo subyacente a las mismas como por sus consecuencias sobre las condiciones laborales del profesorado. La emblemática adicional 15 de la Ley de Reforma de la Función Pública (agosto de 1984), que abría el camino a una carrera profesional (rompiendo el modelo de cuerpo único) y el incumplimiento de la demanda de mejoras salariales (homologación retributiva con el resto de los funcionarios), dos demandas ya «viejas» en el colectivo docente, fracturaron la entente de las organizaciones sindicales con el primer gobierno socialista, ${ }^{35}$ que se quebraría definitivamente cuando,

\footnotetext{
${ }^{35}$ La entrevistas que Julia Varela en Las reformas educativas a debate (1982-2006) (Madrid: Morata, 2006) hace a los protagonistas de aquel proceso treinta años después son extremadamente valiosas, clarificando los distintos planos (sindicales, políticos, administrativos, pedagógicos) que interactúan en los procesos de reforma.
} 
tras el ingreso de España en la Comunidad Económica Europea, las políticas neoliberales (reforzadas tras la firma del Tratado de Maastricht, 1992) y sus consiguientes "planes de convergencia», provocaran brutales recortes en educación, contestados por las grandes confederaciones sindicales (CCOO y UGT) y sus respectivas ramas de educación con tres huelgas generales en esos años (1988, 1992 y 1994).

A lo largo del período de gobiernos socialistas los sindicatos docentes se fueron consolidando y "modernizando", entendiendo por ello que se hicieron claramente representativos (con una participación en las elecciones sindicales bastante elevada, aunque inferior a la del resto de los trabajadores), ${ }^{36}$ se amoldaron al juego representativo con predominio de la negociación sobre la movilización, asumieron la «gestión de las tensiones profesionales» en el sentido expresado por Frajerman, y se esforzaron por ofrecer «servicios» diversos con el fin de aumentar su afiliación, en una dura competencia que a veces anteponía los intereses del sindicato a los del conjunto de los trabajadores del sector; pero también desplegaron toda una gama de actividades, con amplio apoyo en muchos casos, frente a medidas cada vez más lesivas promovidas por las nuevas vueltas de tuerca de las políticas neoliberales, especialmente en esta última década. La reducción de los recursos presupuestarios para la enseñanza pública (en general, para las políticas sociales), un apoyo expreso a los intereses de la enseñanza privada y concertada, fuertes restricciones a los empleados públicos y una contrarreforma educativa en toda regla constituyen una constante a la que los sindicatos han tratado de hacer frente con diversas huelgas generales, si bien cada vez más atrapados entre la necesidad de hacer frente a esas políticas y las dificultades de impulsar una movilización potente contra un "pensamiento único» que insiste una y otra vez en la necesidad de reducir lo público, tildado de carga inoperante, privilegiada y poco competitiva, y en la consideración de las organizaciones sindicales como algo superfluo, obsoleto, con cúpulas y liberados corruptos e interesados sólo en su propio beneficio. ${ }^{37}$

\footnotetext{
${ }^{36}$ En la enseñanza pública no universitaria: 57,2\% en 1994; $62 \%$ en 1998, $60 \%$ en 2002, 57,3\% en 2006 y $52,2 \%$ en 2010 .

${ }^{37}$ Nuestro intento de resumir casi cuarenta años de acción sindical en un par de páginas es una tarea condenada a la caricatura. Remitimos, para un análisis detallado de este periodo, al ya mencionado trabajo coordinado por Octavio Monserrat, Educación y sindicalismo de clase.
} 


\section{QUIÉN, CÓMO Y QUÉ SE INVESTIGA}

¿Quién está hoy interesado en la investigación sobre el sindicalismo docente? Y ¿quién, y para qué, en la de su historia? En un momento de clarísimo declive de la fuerza y el prestigio del sindicalismo en su conjunto - precisamente cuando el poder del capital transnacional ha conseguido, liquidando cualquier forma de resistencia, desatar una ola de enriquecimiento/ empobrecimiento inusitado a escala mundial—, se comprende la valoración unánimemente pesimista que al respecto hacen sus estudiosos. ${ }^{38}$ Sea porque, efectivamente, las organizaciones sindicales constituyen algo «superfluo, obsoleto, con cúpulas y liberados corruptos e interesados sólo en su propio beneficio», sea porque la desmovilización y el individualismo hayan conseguido neutralizar las profecías de una Casandra sindical que ha venido alertando, sin éxito, del retroceso en las conquistas laborales y el desmantelamiento impune de «lo público», lo cierto es que el sindicalismo docente constituye un asunto con escaso "gancho» historiográfico.

Paradójicamente, sin embargo, han sido las reformas educativas neoliberales las que han incentivado los estudios sobre el sindicalismo docente en algunas ocasiones. Así parece haber ocurrido en Latinoamérica, tras las grandes movilizaciones docentes habidas en los años setenta (Argentina y Chile) y ochenta (México y Brasil), movilizaciones cuyo aglutinante — según concluyen los investigadores sociales que las analizaron- habría sido el rechazo a unas reformas que, sobre el supuesto de mejorar la calidad de la educación, estaban diferenciando salarialmente al profesorado, adecuando los contenidos curriculares a los requerimientos de la globalización, promoviendo la descentralización como política deseable y tendiendo prevalentemente hacia la privatización de la educación. Actuar en ese frente y construir consensos en el sector iba a ser un objetivo encomendado entonces a la investigación sobre el sindicalismo docente, según expresa con precisión la investigadora mexicana Aurora Loyo-Brambila:

La descentralización y la ola de reformas educativas de los noventa mostraron hasta qué punto era importante conocer y entender la dinámica de las organizaciones docentes. Los organismos internacio-

\footnotetext{
${ }^{38}$ Manuel Tavares (Portugal), Sadi dal Rosso (refiriéndose a América latina), André Robert (Francia), Laurent Frajerman (Francia), o Alberto Barausse (Italia) hablan —en sus propios trabajos o en reseñas y estados de la cuestión- de «escasez de estudios», «falta de investigaciones empíricas orientadas por hipótesis sólidamente fundamentadas en presupuestos teóricos», «objeto marginado de la investigación histórica y sociológica» y «con escasa presencia bibliográfica».
} 
nales, especialmente el Banco Mundial y el Banco Interamericano de Desarrollo, destinaron fondos para incentivar estudios, seminarios y redes de investigación sobre los sindicatos y las reformas educativas, al tiempo que otro tipo de colectivos reaccionaba con planteamientos críticos hacia las nuevas políticas y se ocupaba de documentar las luchas del magisterio y de sus organizaciones. ${ }^{39}$

Tres proyectos financiados por organismos internacionales apoyaron la elaboración de sistemáticas exploraciones sobre el sindicalismo magisterial, sometido a un riguroso escrutinio destinado a encriptar su realidad en informes que abarcaron a diez países de la región, publicándose una primera sistematización ya en $1999^{40}$ que daría paso a una abundantísima producción historiográfica en la década posterior. Vista con perspectiva, unos años después, en 2008, Loyo arrojaba dudas sobre la centralidad del enfoque adoptado, afirmando que «los sindicatos» y las organizaciones docentes «son importantes no solamente en los procesos de las llamadas reformas educativas» ni su interés se agota cuando los movimientos magisteriales «dejan de ocupar la primera plana de los diarios»; para hacer una decidida autocrítica historiográfica ya en 2011, señalando que «la presión ejercida por las políticas» en el estudio del sindicalismo "ha inducido una distorsión en el campo», marcando sus agendas de investigación y reorientando unos estudios que pasaron de centrarse en su papel de oposición y resistencia a la descentralización durante los años sesenta, a la recepción de las reformas en los noventa; que hay empeño en analizar «la capacidad de diligencia nacional del sindicato para adaptarse a los cambios ocurridos en su entorno» así como en «identificar sus fuentes de poder» - refiriéndose al Sindicato Nacional de Trabajadores de la Enseñanza (SNTE) mexicano-; y, en definitiva, que en el conjunto de la región, por encima de sus diferencias y peculiaridades, la temática de la reforma había ido «señalando zonas de luz y zonas de sombra en las orientaciones de la investigación» para concluir que «reflexionar sobre ello es todavía una tarea pendiente» de los investigadores. ${ }^{41}$

\footnotetext{
39 Aurora Loyo «Sindicalismo magisterial», Revista Mexicana de Investigación Educativa, 13 (37), (2008): 345.

${ }^{40}$ Los proyectos de investigación financiados dieron como resultado publicaciones nacionales y regionales de enorme interés; los resultados de esta primera publicación sistemática, confeccionada con las contestaciones de investigadores locales de Guatemala, Costa Rica, Colombia, Chile, Venezuela, Argentina, Brasil, México, la Republica Dominicana y El Salvador, aparecieron en el monográfico de la revista Propuesta Educativa, 10 (21), 1999.

${ }^{41}$ Aurora Loyo, «La investigación sobre sindicalismo docente en América Latina: una reflexión sobre la diversidad de enfoques», El Cotidiano [en línea] 2011, (Julio-Agosto): [Fecha de consulta: 24 de septiembre de 2014] Disponible en http://www.redalyc.org/articulo.oa?id=32519319011.
} 
Muy lejos de esas dinámicas, la investigación sobre sindicalismo docente ha seguido en España una curva descendente, paralela a la de la afiliación, tras el período de relativo auge que experimentó durante las primeras décadas democráticas, cuando al interés genérico de la época por «rescatar» la historia, se sumó la centralidad que entonces las reformas educativas estaban atribuyendo al profesorado (a «los profesores»), convertidos en un blanco privilegiado por la investigación del momento. Al relativamente numeroso grupo de profesores de Historia de la Educación que entonces se estaba conformando, le correspondió la labor de «recuperar» sus señas de identidad, rescatadas y recreadas en trabajos monográficos, congresos científicos y publicaciones interdisciplinares, cuya extensa producción ${ }^{42}$ deja bien claro que aquel fue un «tiempo de los profesores». Aquellos noveles historiadores de la educación que se interesaban por estudiar los procesos de escolarización lo hacían en ese clima, documentando, desde su mirada hacia la figura docente, un primer «mapa asociativo» cuya temporalidad se cerraba en la guerra civil. La documentación de archivo, que permite identificar, como si de piezas arqueológicas se tratase, la estratigrafía del asociacionismo docente, sus contextos y elementos concomitantes, facilitó — casi materialmente- su interrelación analítica con el proceso más complejo de profesionalización docente, incardinado, a su vez, en el más global de expansión del sistema educativo que estaban analizando. Los trabajos sobre asociacionismo profesional que hemos referido en repertorios previos ${ }^{43}-\mathrm{a}$ los que remitimos para evitar alargar innecesariamente este trabajo- proceden, precisamente, de esa coyuntura. ${ }^{44}$

${ }^{42}$ Imposible de recrear aquí, la nómina de trabajos producidos en los años setenta sobre la figura del profesor desde la perspectiva histórica (básicamente del maestro) es realmente impresionante.

${ }^{43}$ Aida Terrón, «Estatuto socioeconómico y activismo sindical del profesorado», en Nuevas miradas historiográficas sobre la educación en los siglos XIX y XX, eds. Jean-Louis Guereña, Julio Ruiz Berrio y Alejandro Tiana (Madrid: Ministerio de Educación y Ciencia, 2010), 185-208; también hay referencias en: «El movimiento asociacionista del magisterio», "Cien años de defensa colectiva» $\mathrm{y}$ «Associations professionnelles et syndicates dans l'enseignement», Histoire de l'éducation, 78 (1998): 167-197 (monográfico sobre L'Enseignement en Espagne XVIe-XXe siècles, bajo la dirección de Jean-Louis Guereña), y «Circulación de las prácticas de enseñanza entre los docentes. Modos y círculos de sociabilidad profesional de los profesores», en Arte y oficio de enseñar. Dos siglos de perspectiva histórica, ed. Pablo Celada (El Burgo de Osma: Universidad de Valladolid-CEINCE, 2012), vol. I, 257-266.

${ }^{44} \mathrm{El}$ asociacionismo docente ha sido trabajado en España más desde el marco conceptual de la historia social (por historiadores generales e historiadores de la educación) que desde las teorías funcionalista e interaccionistas sobre «la profesión»; si bien esta constituye para Francisco Villacorta una categoría analítica propiamente historiográfica que le permite analizar (en sus trabajos) «el vasto y multiforme panorama de construcción de identidades profesionales, de organización corporativa de intereses y de movilización» en la España del primer tercio del siglo Xx, susceptible de «definir un espacio de la historia 
Insertos hoy en otro contexto educativo, académico y sindical, sin proyectos financiados que lo estimulen y grupos de investigadores específicos que lo articulen e impulsen, el asociacionismo docente "no tiene quien le escriba». Seguimos sin trabajos globales y de larga duración que dibujen su trazo general (algo que nuestros colegas franceses ${ }^{45}$ consiguieron articular ya en los años noventa); carecemos de análisis de la actividad de las mujeres (las profesoras) en la vida sindical, ${ }^{46}$ y está prácticamente en barbecho la historia de nuestras asociaciones más emblemáticas: la Asociación Nacional del Magisterio Primario, las organizaciones falangistas y verticales de los docentes, ${ }^{47}$ el sindicalismo católico pre y postfranquista, ${ }^{48}$ el sindicalismo anarquista, ${ }^{49}$ y las grandes confederaciones sindicales nacidas en la España democrática. Es decir, la tradición del sindicalismo docente en su conjunto, tanto en su corto trayecto libre y democrático como en las oscuras fases de clandestinidad. Lo cual constituye un hecho nada irrelevante si se suscribe la idea de que la carencia de cultura sindical (y de memoria sindical) fragiliza absolutamente la posibilidad de acción y reflexión colectiva del profesorado sobre su propio oficio y el marco y las condiciones en que se desarrolla, ${ }^{50}$

social colectiva, que es la perspectiva última en la que conviene abordar el estudio de las profesiones»; véase Francisco Villacorta "Los grupos profesionales en la perspectiva histórica del siglo XX» en Las claves de la España del siglo XX, dir. Antonio Morales (Madrid: Sociedad Estatal España Nuevo Milenio, 2001), 315-334.

${ }^{45}$ André Robert, Le syndicalisme des enseignants (Paris: Documentation Française/CNDP, 1995); René Mouriaux, Le syndicalisme enseignant en France (Paris: PUF, 1996); Bertrand Geay, Le syndicalisme enseignant (Paris: La Decouverte, 1997).

${ }^{46}$ Casi con la única excepción de los trabajos de Esther Cortada Andreu que documentan la lucha de las maestras en pos de reivindicaciones «sindicales», particularmente la igualdad salarial con los maestros, una conquista (ley de 6 de julio de 1883) precedida de acciones unitarias "de miras y de acción», en «Igualtat salarial i accés al professorat normal: aspiracions y èxits professionals de les mestres estatals durant la Restauració», Recerques: història, economía, cultura, 45-46 (2003): 205-232 (cita en p. 213). También: Ser mestra a la Catalunya del segle XIX. L'escola pública com a espai profesional transgresor (Lleida: Pagès editor, 2006).

47 Antonio Canales Serrano, «Falange y educación: el SEPEM y el debate sobre el bachillerato en los años cuarenta», Educación XXI, 15 (1), (2012): 219-239.

${ }^{48}$ Maria Dolores Peralta Ortiz, «El asociacionismo católico y la educación en el primer tercio del siglo xx español», en Mil gracias derramando, eds. José García de Castro y Santiago Madrigal (Madrid: Universidad Pontificia Comillas, 2011).

${ }^{49}$ Sigue lamentablemente inédita la tesis doctoral de José Nieto Trinidad, El magisterio republicano en la guerra civil española. Aspectos políticos, sociales y culturales (1936-1939). (Universidad de Salamanca, 1994).

${ }^{50}$ Resulta por ello de enorme interés el proyecto de investigación (que desconocemos en su detalle) dirigido por André Robert entre 2000 y 2003 sobre la «utilización de los resultados de la investigación para los enseñantes» titulado «El rol y las funciones de las asociaciones profesionales y de las organizaciones sindicales», con participación de docentes e investigadores del sindicalismo; véase Le syndicalisme en- 
ahondando el perverso círculo vicioso en el que cada vez se ven mas atrapadas las organizaciones sindicales: presionadas para ofrecer «servicios» $\mathrm{y}$ «defensa particularizada» a sus afiliados y posibles votantes — como si de una gestoría o agencia jurídica se tratara-, la dimensión eminentemente sindical se resiente de la falta de un compromiso militante que haga de los sindicatos espacios de propuestas, alternativas, enriquecimiento profesional y defensa colectiva: los «liberados sindicales» constituyen la figura por excelencia de este incapacitante círculo.

En los últimos quince años ha aparecido una reducida nómina de nuevos trabajos, con destacada autoría de sindicalistas e historiadores generales y muy concentrada en el tardo-franquismo y los años inmediatamente siguientes, reflejo del interés suscitado por el fenómeno de la transición política y los movimientos sociales desarrollados en su seno así como el de las organizaciones docentes por documentar su vida institucional. Además de aquellos que cabría incluir bajo la rúbrica de «sociabilidad», ${ }^{51}$ atienden a la perspectiva sindical los de Francisco de Luis, que ha completado la serie dedicada a la historia de la FETE; ${ }^{52}$ de Marta Jiménez Jaén, analizando la dimensión sindical del Movimiento de Enseñantes (y la constitución de los STEs), ${ }^{53}$ dinámica también estudiada por Pamela O’Malley ${ }^{54}$ y por Tamar

seignant et la recherche: clivages, usages, passages, dir. André Robert (Grenoble: Presses universitaires de Grenoble, Saint Fons, INRP, 2004).

${ }^{51}$ Referidos en Terrón, «Circulación de las prácticas de enseñanza». Xavier Motilla ha publicado un completo repertorio sobre esta producción en «Bases bibliográficas para una historia de la sociabilidad, el asociacionismo y la educación en la España contemporánea», Historia de la Educación, 31 (2012): 339-358, de la que excluye la perspectiva que analizamos.

${ }^{52}$ Francisco de Luis, Historia de la FETE (1909-1936) (Madrid: Fondo Editorial de Enseñanza, 1997); La FETE en la Guerra Civil española (1936-1939) (Barcelona: Ariel, 2002); Magisterio y sindicalismo en Cataluña. La Federación Catalana de Trabajadores de la Enseñanza. De los orígenes a la guerra civil (19361939) (Barcelona: Ed. del Serbal, 2006); La FETE (1939-1982). De la represión franquista a la transición democrática (Madrid: Editorial Tecnos, 2009). Hay investigaciones regionales sobre este sindicato, como la realizada por Juan Borroy, Herminio Lafoz y Enrique Satue: Asociación y sindicalismo en la enseñanza en Aragón (1900-1939): la Federación de Trabajadores de Enseñanza (Zaragoza: Fundación Fernando Alaren, 2003).

${ }^{53}$ Marta Jiménez Jaén, La Ley General de Educación y el movimiento de enseñantes (1970-1976) Un análisis sociológico (La Laguna: Universidad de la Laguna, 2000) y «El tránsito hacia el sindicalismo de clase en la enseñanza: CCOO», Anales de la Facultad de Derecho de la Universidad de La Laguna, 22 (2005): 213-234; Marta Jiménez y Manuel Marrero, «Historia de los Sindicatos de Trabajadores de Enseñanza», en Sindicalismo autónomo y asambleario de la enseñanza, AA.VV. (Madrid: Confederación de STEs, 2003), 9-94.

${ }^{54}$ Pamela O’ Malley, La educación en la España de Franco (Madrid: Gens, 2008). 
Groves, ${ }^{55}$ así como por José María Hernández ${ }^{56}$ y por Aida Terrón; ${ }^{57}$ y los de un grupo de sindicalistas que, coordinados por Octavio Monserrat, se han ocupado de hacer la historia del Sindicato de Enseñanza de Comisiones Obreras de Asturias, ${ }^{58}$ un término este que suscribirían sus autores, (inicialmente interesados en hacer el archivo de la organización) y que, irreverente con el rigor epistemológico, expresa bien la tarea - aún pendiente, pero imprescindible para el avance historiográfico- de localización y catalogación de los fondos de las organizaciones históricas del profesorado. Fondos probablemente escasos, dada nuestra traumática historia política y sindical, pero imprescindibles también para nutrir la cultura sindical del profesorado a través de la muestra de sus diversos «rostros», al modo como lo hacen nuestros colegas franceses. ${ }^{59}$

Varios de los trabajos antedichos han utilizado con profusión las fuentes orales y, sobre todo, la prensa profesional y sindical, una fuente que, solo hablando convencionalmente, puede etiquetarse de "esencial» puesto que ella misma es, de hecho, un producto societario, sin cuyo concurso habría sido imposible realizar la mayor parte de los trabajos mencionados. ${ }^{60} \mathrm{La}$ naturaleza misma de la actividad sindical y las condiciones - primero de clandestinidad y luego de improvisación- en que tuvieron que moverse las organizaciones sindicales, reduciendo el registro escrito (Actas, Informes, Estudios, Plataformas) a momentos puntuales y en organizaciones muy institucionalizadas, dejan muy condicionada la acción de los investigadores a la disponibilidad de una prensa sindical que condense el análisis político, la acción y las propuestas programáticas de estas organizaciones. Y sin embargo, esta es una fuente que sigue pendiente de actuaciones colectivas

\footnotetext{
55 Tamar Groves, Teachers and the struggle for democracy in Spain, 1970-1985 (Basinhstocke (UK) y New York: Palgrave Macmillan, 2014).

56 José María Hernández, «Associações de profesores e sindicatos em Espanha durante a transição da ditadura de Franco para a democracia (1970-1983)», Revista Lusófona de Educacâo, 22 (2012): 13-38.

57 Aida Terrón, "Sistema educativo y movilización del profesorado en España”.

${ }^{58}$ Monserrat, Educación y sindicalismo de clase.

${ }^{59}$ Los diversos Coloquios y Jornadas sobre el mundo del trabajo (también el «trabajo docente») han permitido cruzar los diversos rostros del sindicalismo, plasmados en exposiciones como la denominada «Rostros del movimiento obrero» (exposición itinerante y de carácter nacional).

${ }^{60}$ La carencia de documentación sindical de carácter histórico no es menor para el período democrático que para épocas anteriores. El trabajo sobre el Sindicato de Enseñanza de CCOO de Asturias ha tenido como soporte básico su revista Trabajadores de la Enseñanza (años 1978-2014), pudiendo recuperarse en el proceso, con donaciones de sus antiguos afiliados y dirigentes, otra documentación hoy depositada en el sindicato.
} 
que estimulen su conservación y dinamicen investigaciones en un campo historiográfico que se haya completamente estancado, como lo prueban las apenas cuatro nuevas publicaciones realizadas entre los años $2000 \mathrm{y}$ 2013. ${ }^{61}$ Es cierto que algunas actuaciones como el proyecto de investigación «Prensa Pedagógica en España (1785-1939). Repertorio analítico», dirigido por Hernández Díaz, están modificando el estado de cosas (la publicación referida incluye una treintena de trabajos sobre el tema), a lo que podría contribuir también el actual tirón de la arqueología escolar y las actuaciones conservacionistas de materiales históricos-educativos; pero sólo a costa de evitar, en todo caso, el riesgo de su cosificación y fetichización, utilizándolos en su sentido historiográfico más genuino, esto es, en su condición de fuente esencial para reconstruir la historia del asociacionismo y de la profesionalización docente.

\section{ALGUNAS CONCLUSIONES DESDE UNA MIRADA COMPARATIVA}

El derecho de asociación y sus formas prácticas han tenido en España un pasado anormal y convulso que inevitablemente se ha proyectado, marcándolo, a su presente y su futuro: iniciábamos esta exposición aludiendo a ese carácter diferencial que, por ello mismo, resiste mal la comparativa con los países de nuestro entorno. Para la gran mayoría de los españoles, los sindicatos constituían, en 1977, una criatura nueva y desconocida que la democracia, como las cigüeñas, había traído en su seno. Una criatura que, sin embargo, constituía una silenciada experiencia histórica que hubo de forzar su «salida a la luz» (esta era la expresión) impulsada por unas fuerzas de oposición al Régimen que la concebían como elemento estratégico en la lucha política por las libertades en medida no menor que en su condi-

\footnotetext{
${ }^{61}$ Se comparan las publicaciones incluidas en una revisión del año 2000 (aunque publicado en el 2010), Terrón, «Estatuto socioeconómico», y las recogidas por José María Hernández en «Prensa pedagógica y patrimonio histórico educativo en España. Conceptualización y géneros textuales» en Prensa pedagógica y patrimonio histórico educativo. Contribuciones desde la Europa mediterránea e Iberoamérica, ed. José María Hernández (Salamanca: Universidad de Salamanca, 2013), 15-32. No contabilizamos compilaciones de trabajos publicados antes del 2000 aunque reeditados posteriormente (como el de Checa Godoy) o realizados en la década anterior a su publicación, como el de Soledad Montes, La Escuela Moderna. Revista Pedagógica Hispanoamericana (1891-1934) (Barcelona: Pomares, 2003). Los «nuevos» trabajos son los siguientes: Carmelo Real Apolo, «Origen y desarrollo histórico de la prensa pedagógica en Badajoz», Historia de la Educación, 28 (2009): 207-231; José María Mediavilla, Orígenes del periodismo educativo en Toledo (1866-1868). El prisma moderado (Toledo: Ayuntamiento de Toledo, 2009); Milagros Tapia Bon, «La prensa profesional del magisterio en Cantabria (1869-1936)», Cabás, 8 (2012), revista electrónica en línea; Francisco Jiménez Trujillo, La prensa de educación en Málaga (1849-1936). Otra historia de la ciudad (Málaga: Real Academia de Bellas Artes de San Telmo, 2010).
} 
ción (más propia) de instrumento para la defensa de los derechos laborales de los trabajadores (algunos sindicatos se definirían, de hecho, como «sociopolíticos»). Consecuencia de esta congénita marca política será, tras su legalización, un mapa sindical muy dividido (fruto de la estrategia de los partidos políticos por hacerse con los espacios sindicales) que va a condicionar un futuro de muy baja afiliación. El hecho de que las dos grandes centrales sindicales españolas se construyeran, además, de arriba hacia abajo ("primero fueron las siglas y las confederaciones y, luego, un largo proceso de creación, diversificación y reagrupamiento de las estructuras territoriales y confederales que aún no ha acabado", reconocía Javier Doz) iba a contribuir, definitivamente, a la baja densidad característica de nuestro sindicalismo. ${ }^{62}$

Nuestra producción historiográfica está muy lejos de alcanzar el desarrollo que tiene en otros países, particularmente en Francia. En este trabajo nos hemos referido frecuentemente a sus investigaciones, aprovechándonos de sus análisis para avanzar en el nuestro. En este colofón «conclusivo» cabría señalar las razones de su fortaleza, muy relacionadas con el hecho de haber ubicado los análisis sobre el sindicalismo docente dentro del marco más general del «mundo del trabajo», hasta ocupar un lugar "natural» en sus proyectos, coloquios, publicaciones, exposiciones, labor archivística, etc. ${ }^{63}$ Un «método de trabajo» - como lo denomina J. Bertrand- que habría impulsado J. Girault, profesor de la Sorbona, tras la firma de un convenio con la Federación de Educación Nacional y fundar, en 1981, el «Grupo de investigación sobre la historia del sindicalismo enseñante y universitario», iniciando una larga colaboración entre antiguos responsables sindicales de la organización y un núcleo de investigadores procedentes del campo de la sociología y las ciencias políticas. Tras varias décadas de investigación, de recuperación documental, de labor archivística, de Coloquios y Encuentros, el grupo, que daría a la luz una sintética obra colectiva (La Fédération de

\footnotetext{
${ }^{62}$ Javier Doz, «Prólogo», en Montserrat, Educación y sindicalismo de clase.

${ }^{63}$ Hay contribuciones que analizan el sindicalismo docente dentro de obras generales como Frajerman et al., «Les syndicalismes enseignants», y Frajerman, «Syndicalisation et professionnalisation»; el trabajo de Bruno Poucet (dir.), Visages du mouvement enseignant au XXe siècle. Syndicats et associations (Lille: Revue du Nord, Hors série, 20, 2005), surge de un encuentro con motivo de la exposición itinerante «Los rostros del movimiento obrero»; y la obra de Denise Karnaouch, La Presse corporative et sindicale des enseignants. Repertoire. 1881-1940 (Paris: L’Harmattan, 2004) se inserta en acciones globales archivísticas. Se trata de un repertorio exhaustivo de la prensa sindical laica del magisterio, el profesorado de las Normales, la inspección de enseñanza primaria y la enseñanza primaria superior, así como de los boletines de las mutuas nacionales de maestros desde su nacimiento.
} 
l'Éducation Nationale (1928-1992). Histoire et Archives en débat), ${ }^{64}$ ofrecería un importante conjunto de consideraciones sobre el «estado de la cuestión» o balance historiográfico que muestran claramente la madurez proyectiva del colectivo investigador.

Probablemente no exista en España una sola publicación sobre historia sindical que incluya algún capítulo referido al colectivo docente. Tampoco, que yo sepa, ningún convenio con alguna organización sindical del profesorado, ningún grupo de investigadores sobre sindicalismo docente, ningún proyecto financiado. Importa subrayarlo no tanto para admirarnos de nuestra «distancia con Europa» como para entender la dialéctica de «nuestra» fragilidad sindical; e importa mirar hacia un sindicalismo que «ya está investigado» para advertir por donde se puede hacer transitar la investigación. Incluso para advertir sus limitaciones, reconocidas por sus propios especialistas (lagunas en la enseñanza superior; carencias en los planos comparativo, prosopográfico y cultural), así como las necesarias correcciones a introducir: asociar la experiencia de los militantes a la investigación, atender a un mayor desarrollo de las problemáticas ligadas a la profesionalización y orientar la investigación desde los marcos y categorías de la historia social. Unas consideraciones, por lo demás, que (pese a la enorme distancia) guardan algunas coincidencias con las expresadas por investigadores latinoamericanos, también ellos acusando la carencia de marcos teóricos con que afrontar el análisis histórico de las dinámicas sindical y docente. Esto es, cómo imbricar la evolución de los discursos y las prácticas pedagógicas, ${ }^{65}$ los distintos modos profesionales de «ser profesor» y las fluctuaciones de las políticas educativas nacionales,

\footnotetext{
${ }^{64}$ Laurent Frajerman et al. (eds.), La Fédération de l'Éducation nationale (1928-1992). Histoire et Archives en débat (Villenuve d'Asq: Presses universitaires du Septentrión, 2010). Trabajos anteriores serían los de Veronique Aubert et al., La forteresse enseignante: La Federation de l'Education Nationale (Paris: Fayard, 1985) y Guy Brucy, Histoire de la FEN (Paris: Belin, 2003). Sobre el SNES, principal sindicato de enseñanza secundaria en Francia, Alain Dalançon, Histoire du SNES. T. 1, Plus d'un siècle de mûrissement des années 1840 à 1966/7 (Paris: IHRSES 2003), e Histoire du SNES. T. 2, Les années tournant (1967-1973) (Paris: IHRSES, 2007). Sobre el sindicato de enseñanza técnica de la FEN ha trabajado Julien Veyret, y sobre el sindicato nacional de investigadores científicos Michel Pinault; otras asociaciones profesionales han sido analizadas (directores escolares, por Emilie Villemin; profesores agregados, por Yves Verneuil), así como las más importantes mutualidades del profesorado (Dominique Lerch, L'enseignant et les risques de son métier. Un siècle d'histoire associative. L'Autonome de Solidarité 1909-200 (Paris: Sudel Edition FAS, 2003), y Michel Dreyfus, Une histoire d'être ensemble. La MGEN (1946-2006) (París: Eds. Jacob-Duvernet, 2006).

${ }^{65}$ Gonzalo Martín Gutiérrez, Política pedagógica y sindicalismo docente. Análisis de sus relaciones y transformaciones entre 1953 y 1958 (Tesis de maestría: Universidad Nacional de Córdoba, 2011).
} 
siempre condicionadas —explicita o tácitamente- por la acción de las organizaciones sindicales.

A diferencia de ellos (sociólogos y politólogos), los historiadores de la educación son más sensibles a este enfoque, dada su particular perspectiva de análisis; lo expresa claramente Margarida Louro cuando afirma que «el asociativismo de los profesores necesita ser percibido en la evolución de la actividad docente» y dentro «de las estructuras socioeconómicas nacionales en que se desarrolló», ${ }^{66}$ haciendo un preciso enunciado de posición teórica que compartimos plenamente. Probablemente sea por estar ubicados en este plano, por lo que los historiadores de la educación que abrieron este ámbito en Portugal (Rogério Fernándes, António Teodoro, Áurea Adão, António Nóvoa) ${ }^{67}$ tuvieron la sensación — sospecho- de haberse encontrado con el asociacionismo cuando buscaban a los profesores (una experiencia que yo misma comparto); entrar en su análisis fue una manera «interpuesta» de comprender una dinámica profesional en construcción -la profesión docente-cuyamodulación habría que situardentrodesuscontextos concretos. La historiografía posterior ${ }^{68}$ ha mostrado, sostiene Louro, que el juego de planos (de etapas) establecido por las teorías funcionalistas e interaccionistas en el desenvolvimiento de una profesión no ajusta automáticamente y de manera universal cuando se somete al contraste histórico particularizado;

\footnotetext{
${ }^{66}$ Margarida Louro, «O associativismo dos profesores do ensino primário na formação da identidade docente em Portugal (séculos XIX e XX)» en La formazione docente, coord. Genovesi, 143-157.

${ }^{67}$ Rogério Fernándes, O despertar do Associativismo Docente em Portugal (Lisboa: Edições Universitarias Lusófonas 1988); Áurea Adão (O estatuto sócio-profissional do profesor primario em Portugal (1901-1951) (Oeiras: Instituto Gulbenkian de Ciencia, 1984); António Nóvoa, Les temps des professeurs (Lisboa: Instituto Nacional de Investigação Científica, 1987); António Teodoro, Os profesores. Situação profesional e carrera docente (Lisboa, 1990).

${ }^{68}$ Hay un gran paralelismo entre las fases y modalidades del asociativismo docente portugués y el español, reflejo, seguramente de una historia política y sindical con bastantes similitudes. Más temprano en su nacimiento el portugués, impulsado por el regeneracionismo y el republicanismo, se radicaliza ideológicamente durante la república (Gomes Bento, O movimento sindical dos profesores. Finais da Monarquia e I Republica (Lisboa: Ed. Caminho, 1978); tras la dictadura salazarista surgen los «Grupos de Estudo do Pessoal Docente de Ensino Secundario» (GEPDES), un movimiento pedagógico-reivindicativo que anticipa el sindicalismo docente, legalizado tras la revolución de los claveles (Manuel Tavares, «Contribuições para a História do sindicalismo docente, em Portugal: dos Grupos de Estudo, à afirmação e crise do movimento sindical docente», Arquivos Analíticos de Políticas Educativas, 22 (37), (2014) (http.// dx.doi.org/10.14507/epaa.v22n37.2014). Hay activos proyectos de investigación como el implementado por el «Núcleo de Investigação sobre Associativismo Docente» cuya publicación más reciente es la de R. S. Duarte, M. M. C. Ricardo \& M. L. Silva (orgs.), Percursos do Associativismo e do Sindicalismo Docentes em Portugal, 1890-1990. (Lisboa: Edições Universitárias Lusófonas, 2013), y presencia de investigadores portugueses en la "Rede sobre Associativismo e Sindicalismo dos Trabalhadores em Educação», de ámbito latinoamericano.
} 
y que el asociativismo del magisterio - muy determinado por las cuestiones salariales - no fue, en Portugal, el corolario de fases anteriores, sino una temprana respuesta (ya desde 1813) de autoprotección que iba a tener una incidencia muy directa en la formación de la identidad docente del magisterio portugués. ${ }^{69}$

Los análisis de Alberto Barausse ${ }^{70}$ sobre el asociacionismo magisterial italiano nos conducen a una última consideración (conectada con la anterior) acerca de la naturaleza, incuestionablemente política, del asunto que analizamos; a saber, que son las diferencias que operan en esta escala política (las respectivas historias políticas nacionales) las que determinan definitivamente los ritmos, las cronologías, las modalidades asociativas, las orientaciones ideológicas y los programas de acción del asociacionismo docente. Y ese es, también, el espacio en el que debemos situar la cuestión de la identidad docente, algo que aborda en su trabajo Barausse. Es precisamente un proceso político - la unificación de Italia, tras la caída del Imperio austrohúngaro- el escenario que elige el autor para tratar de determinar «la contribución específica (de las asociaciones de maestros) a la formación de los rasgos nacionales de lo que es un profesor» $\mathrm{y}$, como consecuencia, a una especie de «nacionalización» docente, susceptible de impulsar la unificación política y cultural del país. Una hipótesis básica en muchas investigaciones que tiene aquí una nueva «oportunidad» de ser recreada y matizada. A los efectos que analizamos, nos importa advertir cómo la importancia política de esta función (unificación cultural, «nacionalización» de la nación) habría provocado comportamientos completamente disímiles con respecto al sindicalismo docente por parte de los Estados, según momentos y lugares, confirmando esa esencial naturaleza política: prohibido en la España franquista o en el Portugal salazarista, fue, sin embargo, un expresa creación estatal en la Latinoamérica de los años cincuenta, a juicio de la analista Guillermina Tiramonti («en todos los países de la región, a diferencia de lo acontecido en Europa, es el Estado, o los propios partidos,

\footnotetext{
${ }^{69}$ Louro fundamenta estas posiciones en su trabajo Para uma história social do profesorado primario em Portugal no século XIX. Uma nova familia: O Instituto do Profesorado Primario Oficial Portugués (Porto: Campo das Letras, 2008).

${ }^{70}$ Alberto Barausse, «Primary School Teachers'Associations in Italy from Unification to late ninteenth century: origin and development between processes of professionalization and nationalization", History of Education \& Children's Literature, IX (1), (2014): 709-754. Incluye una revisión de la bibliografía italiana sobre el campo. También del autor: L'Unione Magistrale Nazionale. Dalle origini al fascismo (Brescia: La Scuola, 2002).
} 
los artífices de la constitución de un sistema sindical»), ${ }^{71}$ consideración final ésta que apunta a la complejidad del asunto que intentamos dirimir.

\section{Nota sobre la autora:}

Aida Terrón Bañuelos es Profesora Titular de Historia de la Educación en la Facultad de Formación del Profesorado y Educación de la Universidad de Oviedo desde 1978. Investiga en historia regional de la escolarización; genealogía de la cultura escolar; profesionalización, asociacionismo y sindicalismo docente; y perspectiva higienista del currículo escolar. Ha sido vicepresidenta de la Sociedad Española de Historia de la Educación y Premio de Investigación histórica Juan Uría Riu (1987). Algunas de sus publicaciones son: La enseñanza primaria en la zona industrial de Asturias (Oviedo: Principado de Asturias, 1990); «Modifications des programmes et inertie institutionnelle: Tradition et changement dans le modèle scolaire des classes homogènes», Paedagogica Historica, 31 (1), (1995): 125-150; «Associations et sindicats dans l'enseignement», Histoire de l'Education, 78 (1998): 167-197, y La institución escolar: una creación del estado moderno (Barcelona: Octaedro, 2005) en coautoría con Herminio Barreiro Rodríguez.

${ }^{71}$ Guillermina Tiramonti, «Sindicalismo docente y reforma educativa en la América latina de los 90», PREAL, 19 (2001): 6. 